\title{
"A GÓNGORA HACER PEDAZOS, / DEJÁNDOLO TAN ENTERO". CENTONES GONGORINOS EN NUEVA ESPAÑA
}

\author{
"A GÓNGORA HACER PEDAZOS, / \\ DEJÁNDOLO TAN ENTERO". \\ GÓNGORA'S CENTOS IN NEW SPAIN
}

\author{
Martha Lilia Tenorio \\ El Colegio de México \\ mtenorio@colmex.mx \\ orcid: 0000-0002-0021-6632
}

RESUMEN: En Nueva España se escribieron varios centones gongorinos, todos dedicados a la Inmaculada Concepción, y todos como parte de certámenes literarios. Aquí se estudia esa muy particular manifestación poética.

Palabras clave: Góngora; centones; poesía en Nueva España; Inmaculada Concepción; certámenes literarios.

ABstract: In New Spain many of Góngora's centos were written, all of them dedicated to the Inmaculate Conception and all of them as part of literary tournaments. The present aricle studies this highly paricular poetic manifestation.

Keywords: Góngora; centos; poetry in New Spain; Inmaculate Conception; literary tournaments.

Recepción: 26 de julio de 2019; aceptación: 20 de enero de 2020. 
En la Introducción al tomo 2 de sus Poetas novohispanos. Segundo siglo, Méndez Plancarte (1945, pp. xix-xxi) habla de los centones compuestos en Nueva España con versos de Góngora o de Virgilio $^{1}$. Da noticia $-y$ es lo que yo misma he podido encontrar- de siete centones virgilianos y seis gongorinos. Los primeros son: 1) Viridarium poeticum (México, 1669), de José López de Avilés: 26 hexámetros sobre las apariciones de la Virgen de Guadalupe, dentro de una composición mucho más extensa (420 versos) de dísticos latinos; 2) Centonicum Virgilianum, de Bernardo Ceinos de Riofrío (México, 1688): 300 hexámetros, también de tema guadalupano; 3) cuatro mini-centones, cada uno formado por 10 hexámetros, compuestos por ingenios zacatecanos, dentro del certamen Estatua de la paz (México, 1724, ff. 73-80), dedicado a las bodas de Luis I; 4) la inacabada Margileida, de Bruno Francisco Larrañaga (1788): ambiciosísimo centón de 12 cantos, como la Eneida, sobre la vida del venerable misionero Antonio Margil de Jesús ${ }^{2}$.

Los centones gongorinos son: 1) "Visión del capítulo 12 del Apocalipsis", de Agustín de Salazar y Torres (Cítara de Apolo, Madrid, 1694, pp. 259-262): silva de 93 versos, dedicada a la Inmaculada Concepción, "asunto de certamen"; 2) tres silvas, también a la Inmaculada Concepción, parte del certamen Empresa métrica (México, 1665): las tres obtuvieron el primer lugar en su categoría y fueron compuestas por Juan de Guevara, Alonso Ramírez de Vargas y Félix López Muñiz, de 132, 148 y 89 versos, respectivamente; 3 ) dos canciones, otra vez a la Inmaculada, dentro del certamen Triunfo parténico, una de Francisco de Ayerra y Santamaría (primer lugar) y la otra de Alonso Ramírez de Vargas (segundo lugar), las dos de 74 versos. Aquí estudio los seis centones gongorinos.

1 Para ver una edición completa de todos los centones gongorinos novohispanos, se puede consultar Tenorio 2019.

${ }^{2}$ De hecho es éste el único centón hispánico mencionado en lo que se supone un catálogo de todos los centones latinos de la tradición occidental. Me refiero a Revue analytique des ouvrages écrits en centons, depuis les temps anciens, jusqu'au XIXième siècle (Delepierre 1868, p. 398). Ahí se dice que Larrañaga "fit publier au Mexique, en 1788, de prospectus d'une Enéide apostolique, ou épopée-centon destiné à celebrer les travaux du missionnaire Antonio Margil de Jesús... Ce poème, dit-il, sera nommé Margileida, et écrit en purs vers de Virgile, qu'il se propose de traduire en Castilian, et de publier par souscription, pour l'Amérique septentrionale. Ce prospectus, très developpé, annonce que l'ouvrage formera trois volumes in $4^{\circ} \ldots$... 
El término cento proviene del griego kentron, 'aguja'. El Oxford Latin Dictionary lo define como "a garment of several bits or pieces sewed together" (Lewis \& Short 2002, s.v.) es decir, una pieza textil compuesta de varios retazos. De ahí, el término se desplazó semánticamente para significar composiciones formadas por fragmentos tomados de uno o más poetas. El género apareció por primera vez hacia el siglo III; floreció en la Antigüedad tardía, con alguna presencia en la Edad Media, cierta revitalización en el Renacimiento ${ }^{3}$ y muy ocasionales apariciones posteriores (por eso, precisamente, llaman la atención los centones novohispanos, casi todos del siglo xvil y algunos de comienzos del siglo XVIII). Los centones más famosos son los de la Antigüedad tardía, compuestos a partir de Homero o de Virgilio: "Virgil and Homer are the characteristic source-texts in the respective traditions [latina y griega] by virtue of their canonicity: These are the texts, above all others, hard-wired into the ancient reader's brain" (Hinds 2014, pp. 171-172).

Estrictamente hablando, los primeros ejemplos de centón griego son dos breves pasajes en las Ranas de Aristófanes: vv. 1285-1295, hecho con versos de Esquilo; vv. 1309-1322, con versos de Eurípides (Prieto Domínguez 2010). El primer testimonio de centón latino es de la época de Tertuliano (siglos II-III), quien da noticia de la tragedia Medea, de Osidio Geta (s. III), compuesta con versos virgilianos (Lamacchia 1996, pp. 733-737). A los siglos IV-v pertenece el centón de la emperatriz Eudocia con versos de Homero, éste de tema bíblico ${ }^{4}$. En latín, se hicieron centones también con versos de Ovidio y Horacio $^{5}$, pero Virgilio fue, con mucho, el autor más "centonizado" (McGill 2005). Tal vez los centones más famosos sean, entre los

${ }^{3}$ El Renacimiento, con su vuelta a la tradición clásica, "favorisé la naissance d'une écriture fondée dans une large mesure sur l'imitation, donc de caractère essentiellement intertextuel: dans pratiquement chaque œuvre littéraire, qu'elle soit en vers ou en prose, la présence de références à d'autres textes est à la fois marquante et évidente, et capitale pour la construction de son sens" (BAŽIL 2009, p. 83).

${ }^{4}$ Según Filippo Ermini (1909, pp. 29-30), "i centoni omerici di argomento cristiano nel medio evo furono effetto dell'imitazione dal latino, ben maggiore importanza ebbero i centoni latini e specialmente vergiliani nella letteratura occidentale".

5 Palmer (2014, pp. 196-197) da noticia de un centón anónimo de 26 versos, a partir de Lucrecio, y en honor a este mismo, que figura como parte 
latinos, el Cento nuptialis de Ausonio, escrito para celebrar la boda del emperador Graciano en el año 374; o el Cento de Falconia Proba, matrona romana del siglo IV, convertida al cristianismo en su vejez, que relata con el lirismo de la épica virgiliana el Antiguo y el Nuevo Testamento. Entre los centones griegos, destaca el ya mencionado de Eudocia.

El manifiesto poético más importante y sistemático de lo que constituye la práctica centonaria es el prefacio de Ausonio a su Cento nuptialis: "Centonem vocant, qui primi hac concinnatione luserunt. Solae memoriae negotium sparsa colligere et integrare lacerata, quod ridere magis quam laudare possis" (1999, pp. 145-149). Un poco más adelante viene una sucinta, pero metódica descripción de la técnica del centón:

Y si me permites que te enseñe -yo que debo ser enseñado- qué es un centón, lo haré. Con pasajes variados y sentidos diferentes se suelta una estructura de poema, de modo que estén unidos, en un solo verso, dos cortados o uno cortado y la mitad del siguiente con otra mitad. Pues colocar dos unidos es una torpeza, y tres de un tirón, una bobada completa (1990, t. 2, p. 45).

La caracterización del centón por parte de Ausonio como solae memoria negotium, "un asunto estrictamente de memoria", explica bien el lugar que esta forma literaria ocupa en la historia de la literatura clásica. El género requiere que tanto el escritor como el lector recuerden fragmentos poéticos desgajados de sus contextos originales; ejercicio que muestra la influencia de las prácticas didácticas y pedagógicas que cultivaban el análisis laborioso de pasajes de autores canónicos, disciplina que promovía el uso de intertextos literarios en el discurso culto:

A ben osservare, il centon strictu sensu non è che l'estrema conseguenza de un ensegnamento scolastico che, proponendo al giovane una cultura basata sull'imitazione dei modelli classici e invitandolo a riprodurli attraverso le norme della memoria dotta e dell'arte allusiva, creava nei meno capaci una forma mentis che nell'esercizio della aemulatio, nella gara coi grandi poeti, si accontentava di conglutinare, variamente contaminandoli fra loro, passi e versi che la memoria facilmente (e passivamente) offriva, piuttosto che crearne ex novo (Lamacchia 1996, p. 734).

de los preliminares en una edición italiana de De rerum natura (Verona, 1486, f. vii). Que yo sepa, nadie más da noticia de este centón lucreciano. 
El centón es, pues, la extensión lógica de esta práctica: la manipulación memoriosa de autores anteriores da cuenta de qué manera sus obras servían como "pactos" entre los lectores que los entendían como fuentes de una lengua autorizada y que autorizaba.

La habilidad del poeta centonario consistía, entonces, en lograr reducir a variaciones mínimas sus propias intervenciones en el texto modelo, justificado por la exigencia de sus temas (que no eran, obviamente, los del poema original). Así, el valor literario del centón estaba determinado por la literalidad con que se recrearan los versos de Virgilio o de Homero. De hecho, en el ya mencionado prefacio a su Cento nuptialis, Ausonio compara la composición de centones con el juego conocido como "ostomaquia" $"$

Son unos huesecillos: en conjunto tienen catorce figuras geométricas... Con diferentes uniones de estas piezas se componen figuras de mil tipos: un elefante salvaje o un jabalí, un ganso volando y un mirmilón armado, un cazador emboscado y un perro ladrando, o bien una torre y un cántaro, y otras innumerables figuras de modo semejante, que varían si un jugador es más hábil que otro. Son asombrosas las combinaciones de los expertos; ridículas las uniones de los inexpertos (1990, t. 2, pp. 45-46).

El juego está relacionado con Arquímedes y también se le conocía como loculus Archimedius:

Il gioco è in practica una variante più complessa del tangram cinese, oggi più fortunato: anziché in sette suddivide in fatti il quadrato in ben quattordice pezzi dalle diverse forme geometriche, che consentono un numero de combinazioni praticamente illimitato e possono dar vita alle più varie figure, dall'elefante al cinghiale, dall'oca al gladiatore, dal cacciatore al cane e cosí via (Polara 1990, p. 272).

Es importante señalar la relación con la geometría, pues implica que la composición de centones no consiste nada más en amontonar versos de diversas procedencias, sino en darles una forma nueva en relación con el modelo, una forma

${ }^{6}$ Explica A. Alvar Ezquerra, en la citada edición (Ausonio 1990, t. 2, p. 45), que el término se traduce como "combate de huesos", "juego comparable a nuestro puzzle". 
lógica, congruente. No es sólo la aplicación mecánica de versos ajenos; la habilidad tiene que trascender el aspecto meramente técnico. Se trata de la confianza de un poeta (en este caso Ausonio) en la palabra de otro poeta (en el Cento ausoniano, de Virgilio); de la capacidad intrínseca de la lengua y sus expresiones de ofrecer la ambivalencia de significado que permite que aquellos pasajes tomados sean capaces de remitir a situaciones sustancialmente diversas ${ }^{7}$. Son, pues, muchas las dificultades que hay que superar: "era preciso recoger fragmentos diversos, cortados por lugares predeterminados, que tuviesen sentido y concordancia gramatical entre ellos, y que las mutaciones semánticas que los términos se ven obligados a sufrir para adaptarse a un sentido, no acusen violencia" (E. Montero Cartelle, "Introducción" al Centón nupcial, apud Parra García 1999, p. 365). Esta "adaptación" implicaba muchas veces -aunque teóricamente no era lo deseable u ortodoxo- cierto tipo de alteraciones, por mínimas que fueran, gramaticales, semánticas, métricas, prosódicas, a veces léxicas.

Según Giovanni Salanitro (1997, pp. 2322-2323), las reglas del centón son las siguientes:

1) La primera, de carácter general, "non inserire nel centone frasi o anche semplici parole que non siano tolte de Virgilio [o del autor centonizado]".

2) La segunda regla, de carácter más técnico, exige a los poetas centonarios una precisa yuxtaposición de versos o hemistiquios para evitar incorrecciones métricas. Aquí entra la pres-

${ }^{7}$ El Cento nuptialis, por ejemplo, usa los versos del "casto" Virgilio para contar la noche de bodas y el desfloramiento de una doncella. Mucho más tarde, en pleno Renacimiento, Lelio Capilupi (1497-1560) compuso el Cento ex Virgilio Gallus, cuyo tema es la unión amorosa de dos jóvenes amantes, Gayo y Deyopeya, unión, a diferencia de la narrada por Ausonio (a la que precede una boda), puramente casual y pasajera. En la parte que cito, Gayo intenta seducir a Deyopeya (tomo el texto latino de PARRA GARCía 1999, pp. 363-412): "Accipe daque fidem. / Quoniam convenimus ambo, / vis ergo inter nos quid possit uterque vicissim experiamur? / ... / Telum immane manu valida quod forte gerebat / eripuit mulcens, / quo non praestantius ullum / Europa atque Asia, / visu mirabile monstrum / horendum, et / cui turpe caput, cui plurima cervix, / consertum tegmen spinis, / prolixque barba / et crurum tenus a mento palearia pendent. / Tantae molis erat. / «Me ne huic confidere monstro?» / ... / Paret amor dictis. / Caeli in regione serena / intonuit laevum, sonat una laetifer arcus. / Constitit hic, / curvo derexit spicula cornu / nulli visa cito, / perque ilia venit harundo / et laevo infixa est lateri, / mirabile dictu" (vv. 96-112 y 137-141). Sin comentarios. Y la mayoría de los versos provienen jde la Eneida! 
cripción de Ausonio de no usar dos hemistiquios o versos que sean consecutivos en el original, pues usándolos por bloques -como veremos que se hace en los centones gongorinos novohispanos- se evita buena parte de la dificultad que implica el centón: ya de origen vienen trabados sintáctica, semántica y métricamente. Cuando no se acata esta regla, el poeta no tiene que buscar la manera de hacer funcionar los versos ajenos, pues ya funcionaban en el texto original. Este recurso es tramposo y de "bobos", dice Ausonio.

3) La tercera regla tiene que ver con la cesura: si van a usarse hemistiquios, hay que hacer el corte donde las cesuras (generalmente la pentemímera) lo posibiliten. No sólo en el hexámetro latino es importante cortar el verso donde prosódicamente hay cesura, también en los endecasílabos hispánicos (sexta sílaba).

Por todos estos requerimientos técnicos, la poesía centonaria se caracteriza por la repetición (usar varias veces los mismos versos o hemistiquios), las numerosas incongruencias léxicas, la audacia o poca naturalidad de las "suturas" entre los pedazos, las frecuentes alteraciones semánticas ${ }^{8}$ y ciertas anomalías prosódicas y métricas. De ahí que para muchos estudiosos se trate de un género menor, un "esercizio scolastico inferiore" (Giorgio Pasquali, Arte allusiva, apud Lamacchia 1996, p. 734), sólo útil -en el caso de los centones griegos y latinos- como testimonio secundario de la transmisión textual de Homero o de Virgilio. Sin embargo, a partir de las ideas del propio G. Pasquali sobre el arte alusiva ${ }^{9}$, de la moderna "intertextualidad" o del muy sugerente análisis de Gian Biagio Conte sobre la función retórica y estilística de la alusión ${ }^{10}$, se puede apreciar el valor de los centones "por su capacidad de relectura literaria, lo que lo[s] convierte en un ejemplo extremo de los alcances del fenómeno de la intertextualidad"

${ }^{8}$ Como se vio en el centón de Lelio Capilupi, en el que el telum ('dardo') que Gayo trae entre manos significa una cosa totalmente distinta.

9 Según G. Pasquali, la característica particular de la alusión es el hecho de que el autor busca que el lector reconstruya con precisión el texto evocado. El filólogo distingue entre la alusión, voluntaria e indicada explícitamente, la reminiscencia, que puede ser involuntaria o inconsciente, y la imitación, que no siempre se busca que sea reconocida (PASQUALI 1968, t. 2, pp. 75 ss.). En este sentido, puede ser que el centón sea el ejemplo por antonomasia del arte alusiva: el poeta centonario emprende un trabajo consciente, voluntario, deliberado, y espera que el lector haga lo mismo.

10 "Allusion, we mantain, performs rhetorical functions similar to those performed by certain figures of speech” (CONTE 1986, p. 40). 
(Prieto Domínguez 2008, p. 137). La intertextualidad del centón es única, por ser absoluta y establecer estrechos vínculos con la fuente original. Ninguna otra forma literaria se compromete con algún autor, uno solo, tan evidente, persuasiva y exclusivamente.

Según explica Óscar Prieto Domínguez (2010), el análisis de este tipo de composiciones dio un giro cuando F. Desbordes entrevió su vinculación con la intertextualidad e hizo énfasis en que se trataba de un nuevo texto, puesto que "changer le contexte, c'est changer le texte" (p. 15). A fin de cuentas, el centón se presenta como un texto nuevo que, aunque mezcla versos ajenos, los organiza de otra manera, preñando de sentido la nueva combinación o estructura, pues los contenidos no sólo son otros, sino radicalmente distintos a los de los modelos originales: "Alludere ad un autore precedente diventó il mezzo più idoneo per evocare particolari situazioni liriche o dramatiche, e spesso i poeti si compiacquero di accogliere in testi nuovi citazioni antiche che crassero col texto nel quale venivano inserite una certa tensione stilistica ed espressiva" (Lamacchia 1958, p. 195). Es el centón "el grado más complejo de la alusión" (Prieto Domínguez 2008, p. 138). Aunque, como explica Giovanni Polara (1990, p. 246), hay que "valutare meglio le differenze tra l'aemulatio del centonista e quella degli altri poeti" y acentuar los aspectos técnicos de la composición y, sobre todo, el "significato dell'operazione messa in atto con la riutilizacione di versi e sezioni di versi preesistenti".

Así, pues, hay que estudiar el centón como una variante muy particular del arte de la alusión. Comenta Gian Biagio Conte (2017) que cuando fue acusado por sus frecuentes hurtos de Homero en la Eneida, Virgilio, supuestamente, respondió: "it is easier to steal Jupiter's thunderbolt or Hercules' club than a line from Homer" (p. 5). El mantuano no sólo no niega los hurtos ('plagios'), sino que subraya que no cualquiera puede hacerlos, por lo que espera que se reconozcan y se admiren. Esta operación de robar versos ajenos y de apelar a que el lector reconozca el robo y lo admire es, precisamente, el núcleo estético del centón. Para que un centón funcione de verdad se requiere que el lector capte las alusiones y reconozca la obra de donde provienen y su contexto original:

necesita de un lector activo, capaz de desentrañar el interminable juego alusivo creado para poder construir así el significado último 
y verdadero del centón, el significado secundario oculto tras la erudición intertextual, que matiza, explica y, en parte, difiere del sentido lineal que obtenemos si nos limitamos a una mera lectura (Prieto Domínguez 2010, p. 15).

Para entender realmente el significado de los centones, los lectores deben estar conscientes de su dualidad semántica: al desgajar versos (de Homero, Virgilio o Góngora) de sus contextos originales y colocarlos en nuevos discursos, se provoca el mismo fenómeno que el uso de figuras estilísticas produce sobre la lengua de todos los días, cierto efecto de "desfamiliarización", que obliga al lector a poner atención en los cambios de significado operados en sus viejos y conocidos versos de siempre; a fijarse en ellos, de nuevo, negociando su significado en la constante vinculación con la fuente original: "The readers of the Latin centos are therefore expected to approach these «verse jigsaw puzzles» with profound knowledge of Virgil's poetry; otherwise, they cannot relish the unique interplay of meanings, which contributes to the richness and complexity of the narratives told" (Okáčová 2009, p. 4).

Evidentemente, la condición para que se reconozcan las alusiones es la familiaridad con los modelos, de ahí la elección de poetas canónicos, aquellos cuyos versos llenaron la memoria poética y el imaginario de autores y lectores contemporáneos o posteriores: o porque se enseñaban en la escuela, o porque eran los más leídos, o por las dos cosas. Es, pues, el centón el lugar donde la literatura se produce, se recibe y muestra su andamiaje, sus principios de operación:

Centonist themselves would no doubt agree that their works are strange and parasitic, and that the texts fail to measure up to the aesthetic standards of great literature. Indeed, by their very nature the centos are and do very different things from what conventional high poetry is and does. Critics should bear this in mind and approach the works on their own terms (McGill 2005, p. xvii).

Marie Okáčová (2009) concluye su estudio sobre el género con una afirmación que me parece un buen punto de partida para analizar esta sui generis forma poética: "In fact, as an example of intertextualiy par excellence, the patchwork poetry is, at least conceptually, a highly innovative literary form" (p. 5). 
Se componen, igual que los paganos, preponderantemente con versos de Homero, Virgilio o (mucho más tarde) de Góngora, pero su argumento es cristiano, por lo que resultan muy diferentes en su inspiración, además de que tienen una finalidad claramente didáctica y de celebración doctrinal. En estas composiciones no sólo es necesaria la complicidad literaria, sino también ideológica y devocional, entre lector y autor. Los poetas centonarios cristianos no se ciñen únicamente a usar versos conocidos por todos, pues además articulan creencias compartidas por la comunidad para la cual escriben. La poesía de Homero o Virgilio, aunque ajena al mensaje cristiano, era la poesía heroica por excelencia, y por el momento de la historia del cristianismo en que los centones religiosos surgieron ( $c a$. siglo IV), "i più degni e i più idonei a celebrare l'epos cristiano e a edificare l'assemblea dei neofiti" (Lamacchia 1996, p. 735). De esta manera se lograban dos objetivos: uno, demostrar que la poesía épica, el más alto género poético, podía ser vehículo de la doctrina cristiana; dos, aprovechar esas formas (homéricas o virgilianas) ya conocidas y la técnica de desfamiliarización del centón para dejar más fácil y fuertemente impreso en los lectores el mensaje doctrinal. Señala Martin Bažil (2009, p. 18) que Proba misma (autora del centón cristiano más famoso y estudiado) y su editor y prologuista del siglo IV insisten en la función reinterpretativa e incluso correctiva del centón: "Vergilium cecinisse loquar pia munera Christi" (Cento, v. 23), escribe la poeta en el prólogo a su Centón. Su editora moderna comenta muy atinadamente este verso en su introducción:

La centonaria intende mostrare come i versi e gli emistichi virgiliani, opportunamente selezionati e ricollocati, possono esprimere i contenuti più alti della religione cristiana, offrendo ad un pubblico di colti neofiti un carmen sacrum che recuperi la dolcezza della poesia pagana grazie alla sacralità dei contenuti cristiani (Sineri, 2011, s.p.).

Como se ejemplificó con el centón renacentista de Lelio Capilupi, muy frecuentemente la intención del centón pagano es la parodia-homenaje del modelo. Esa distancia irónica está completamente ausente en los centones cristianos: usan la tradición con seriedad y veneración para legitimar su mensaje. 
"Precisamente es esa seriedad lo que limita su capacidad alusiva al no remitir a la tradición de la que se apropia", dice Prieto Domínguez (2010, p. 66), quien piensa que la intención fuertemente doctrinal y didáctica influye negativamente en la calidad literaria de estas composiciones, puesto que desaparece "el recurso a la complicidad pícara del lector" $(i d$.$) . Con todo,$ como señala muy bien G.H. Tucker (2013, p. 152): "the centoform was not simply to be confused with parody either, even if sharing the fundamental aspects of a transformative (miss) appropriation of a source-text (affecting both verbal surfacetex $[$ verba] and subject-matter [res] )". Paródico o no, el contexto original siempre entra en juego; el significado del centón se negocia, como en los paganos, en la vinculación al modelo. En realidad, la complicidad con el lector no desaparece: cambia de valencia, se hace más erudita y comprometida ideológicamente; el ejercicio intelectual que tiene que hacer el lector es más exigente, pues la operación de desfamiliarización de los versos clásicos es mucho más profunda. El lector no sólo debe haber interiorizado completamente los textos homéricos o virgilianos, no sólo debe ser capaz de reconocer y reconstruir los contextos originales, sino reconstruir, gracias a la devoción compartida, la operación alegórica que implica cargar con contenidos cristianos versos eminentemente paganos. Como dice muy bien Rosa Lamacchia (1958, p. 216), los centones cristianos son "esibizione in veste pagana di una dottrina cristiana, nella quale l'allusione si riduceva per lo più ad allegoria, e al giuoco si sostituiva la pietà".

No son muchos los centones paganos; tampoco los cristianos. Giovanni Salanitro (1997, pp. 2338-2340) da noticia de tres centones cristianos con versos de Homero, los tres de tema bíblico (la salvación del hombre, la vida de Cristo y el Viejo y el Nuevo Testamento). Rosa Lamacchia menciona cuatro virgilianos (el ya comentado de Proba y otros tres: sobre la creación del mundo, la Encarnación y la Iglesia ${ }^{11}$ ). La importancia de los

11 Señalo los temas porque los centones novohispanos sólo son religiosos, y sus asuntos, predominantemente marianos; strictu sensu, sus contenidos no son bíblicos ni ortodoxamente teológicos: la Inmaculada Concepción y las apariciones de la Virgen de Guadalupe. Un caso algo diferente es el centón de la poetisa francesa Anne Musnier (principios del siglo xıII) que "célèbre le souvenir de un événement historique..., qui n'est pa rapporté ni par les historiens, ni par les érudits de ce pays [Francia]" (DELEPIERRE 1868, p. 141). El suceso celebrado es la buena fortuna de Enrique el Libe- 
centones cristianos está en que a través de ellos la cultura cristiana se relacionó con la poesía clásica y se hizo de una lengua poética, lo que permitió el nacimiento de la poesía cristiana que se cultivó durante la Edad Media y, luego, el Renacimiento:

La poesía cristiana -dejando a un lado la poesía hímnica, que tiende a integrarse en la liturgia- adoptó con tanto o mayor entusiasmo que la pagana, la lengua, las fórmulas y la métrica de Virgilio, de Horacio, de Ovidio. Un afán de competir con la literatura profana, un deseo más o menos confesado de desquitarse de los paganos cultos a quienes la rusticidad de la lengua de las Escrituras movía a desdén, un interés por demostrar que la doctrina del cristianismo era capaz de revestirse de los mismos admirados ornamentos que sustentaban ideas paganas -lo que en el fondo llevaba ingenuamente implícita la confesión de que eran esas formas, por cierto paganas, las que ennoblecían- influyeron mucho en aquella decisión (Vidal 1973, p. 53).

\section{LOS CENTONES GONGORINOS}

Lo primero que hay que señalar es que en el Barroco hispánico el centón tomó "un segundo aire", en cuanto concepto, es decir, construcción conceptista ingeniosa, por la operación intelectual que implica relacionar en un mismo verso contextos y mensajes muy dispares. En segundo lugar, debe subrayarse la dignidad de clásico que se da a Góngora, en el mismo nivel que Homero y Virgilio, pues, en español, prácticamente sólo se hicieron centones a partir de versos de Góngora ${ }^{12}$. El conceptismo y la lengua

ral, conde de Champaña, al haberse salvado de un complot en su contra ( $c a .1175)$. La curiosidad de este centón es que usa versículos del Antiguo y Nuevo Testamento, es decir, de procedencia religiosa, para celebrar un hecho histórico: "Malgré l'absence du rythme, on y trouve une forme éminemment poétique, et il constitue, dans son ensemble, un petit drame plein de mouvement et de vie" (Delepierre 1868, pp. 142-143).

12 Según Antonio Carreira (2010, p. 410), en toda la tradición hispánica sólo dos poetas merecieron los centones: Góngora y Virgilio. GERARDo Diego (1927, p. 25) incluye también a Garcilaso: "que yo sepa, únicamente de Garcilaso y de Góngora se han hecho centones tejidos con sólo versos del poeta". Por su parte, Miguel Herrero (1939, p. 232) dice: "Los honores tributados a Virgilio y a Garcilaso de formar con sus versos centones acomodados a diversos asuntos, no faltaron tampoco a don Luis de Góngora". Jesús Ponce Cárdenas (2008, p. 144) da noticias de un centón de versos de Garcilaso: Cristo Nuestro Señor en la Cruz, hallado en los versos del príncipe de 
del cordobés crearon por sí mismos una tradición discursiva: un repertorio de hábitos expresivos, de posibilidades y preferencias estilísticas; una gramática lírica y memoria letrada nutrida por sus versos. Después de Virgilio, nadie más leído, más admirado, más venerado, más aprendido de memoria que Góngora ${ }^{13}$. No podía ser otro el poeta proveedor de versos para centones. Creo que este hecho no se ha resaltado suficientemente.

$\mathrm{Al}$ parecer, los primeros centones gongorinos se compusieron en España, y el primero -cosa que no es de extrañar- en honor al mismo Góngora. Se trata de las composiciones de Angulo y Pulgar: "Égloga fúnebre a don Luis" (1638) y "Elegía a doña Isabel de Borbón" (1644). También español, aunque algo más tardío (1680), es el Epitalamio real a las bodas de Carlos II, de Juan de Vera Tassis ${ }^{14}$. Víctor Infantes (1990, p. 116) da cuenta de cuatro sonetos-centones con versos de Góngora, anónimos, compuestos para el túmulo dedicado al predicador Antonio Vieira en 1697. Infantes piensa que la composición de estos centones españoles y portugueses pudiera deberse al influjo de los centonistas de Petrarca, moda italiana de la segunda mitad del siglo Xvi:

Petrarca, el gran Petrarca, alterna y sustituye a Virgilio, el gran Virgilio. El centón poético... no tiene que recrear los versos inmortales de los poetas clásicos, la obra de autores modernos-conocida y divulgada por toda la Europa culta- puede suplir como modelo una perfección que alcanzará a nombres medievales y renacentistas; sin caer nunca en la tentación de suponerse a la altura de la usurpación... (pp. 116-117).

De esta reflexión hay que destacar dos hechos: el primero, el surgimiento de los "clásicos modernos" como "modelos de per-

nuestros poetas, Garcilaso de la Vega, sacados de diferentes partes y unidos con ley de centones (Madrid, 1628), de Andosilla Larramendi.

${ }^{13}$ Ya en el último tercio del siglo XVIII, un neoclásico como Francisco Javier Alegre (traductor del Arte poética de Boileau) habla en los siguientes términos de Góngora: "Homero y Virgilio, hablando en castellano, no pudieran haberlo dicho mejor" (2016, p. 233).

14 Epitalamio real a las prósperas augustas sacras bodas de las cathólicas Magestades... Fórmale con solos versos mayores de D. Luis de Góngora, siguiendo el método de sus Soledades; con precisión de poner más que dos versos juntos, y no añadir ni quitar sílaba (GALLARDo 1889, t. 4, col. 1023). Miguel Herrero, a partir de la información de Gallardo, menciona esos mismos tres centones: los dos de Angulo y Pulgar, y el de Vera Tasis, este último mal atribuido al conde de la Roca (misma confusión de Méndez Plancarte 1945, t. 2, p. xx). 
fección" equiparables a los poetas clásicos, esto es, tan reconocidos y reconocibles, tan difundidos, estudiados y memorizados, tan autorizados y tan capaces de autorizar a sus seguidores. Insisto, parafraseando a Infantes: en español, "Góngora, el gran Góngora, alterna con Virgilio, el gran Virgilio" (en realidad, no lo sustituye, pues los centones latinos españoles eran, fundamentalmente, virgilianos). El segundo hecho es la actitud de los poetas centonarios frente a su modelo, conscientes de no estar a la "altura de la usurpación": homenaje, veneración, reconocimiento de la calidad y de la potencia semántica de los versos evocados.

Las composiciones resultantes, esto es, los centones gongorinos, son una nueva entidad textual: muestran en su superficie un ensamblaje evidente de partes reconocibles que se mantienen separadas unas de otras (puesto que provienen de diferentes pasajes u obras del modelo), al mismo tiempo que se traban en un nuevo conjunto semántico, dentro del cual se relacionan de otras maneras. Nuevos sentidos corren -y no clandestinamente, como es el caso de la reminiscencia o de la imitación, sino de manera confesada y ostentosa- por los versos gongorinos; nuevas iuncturae y nuevos ritmos derivan de aquellos mismos versos, más que probados, al recontextualizarlos y cargarlos con otros sentidos, no sólo nuevos, sino diametralmente opuestos.

Recapitulando, se puede hablar de siete centones gongorinos peninsulares: tres de poetas españoles y cuatro de poetas portugueses. Aquí viene lo que más llama mi atención: los otros seis centones gongorinos de que se tiene (o tengo) noticia se compusieron en Nueva España -la estela de Góngora se vivió de manera particularmente fecunda e intensa en los siglos XVII y XVIII ${ }^{15}$.

15 De hecho, Jesús Ponce Cárdenas (2008), de los ejemplos novohispanos, sólo menciona el centón de Salazar y Torres (con toda seguridad compuesto en Nueva España -como se verá más adelante-, pero publicado en España) y el de Francisco de Ayerra y Santamaría, publicado en el Triunfo parténico. Por su parte, Víctor Infantes (1990), además del de Salazar y Torres, menciona las dos canciones del Triunfo parténico, sin nombre de autor. Ninguno de los dos parece conocer el artículo de IRving A. LEONARD (1929), donde se da el nombre de los autores y se reproducen los dos centones. Igualmente hay que recordar que el centón virgiliano cristiano también fue muy cultivado en suelo novohispano (siete composiciones; véase supra). 
Como en el caso de los centones latinos y griegos, los gongorinos se han visto como mero ejercicio escolar, de escaso valor literario: "Tales ejercicios no pueden reportar beneficio poético alguno, pero sí revelan una devoción a prueba de paciencia y en los casos o fragmentos más afortunados, un alarde de ingenio" (Diego 2003, p. 72). Irving A. Leonard, quien da noticia en 1929 -al parecer por primera vez- de los centones gongorinos del Triunfo parténico -no conoció los de la Empresa métrica, ni el de Salazar y Torres-, emite el juicio más severo, en mi opinión injusto, ninguneando el fenómeno sin explicarlo:

It is easier, however, to point to the more ridiculous manifestations of the vogue of Góngora in the New World than it is to discover apologists and critics. This is especially true in Mexico. The blighting effect of his influence upon the literary activities of the poets and versifiers is here all too apparent in the surprising number of poetical compositions which a strange vagary of Fate has permitted to survive the ravages of Time and a deserved neglect. The fact that few modern anthologies of Mexican poetry contain numerous selections from the seventeenth century is significant; it is likewise indicative of the poverty of inspiration which is associated with such literary productions at the time. The sterility and barrenness of this period is indeed depressing (p. 564).

A su vez, Méndez Plancarte (1945, t. 2, p. xx) sólo comenta: "son los centones la mayor pleitesía que una generación tan encendida de Góngora podía rendirle, como antaño a los máximos poetas [esto es, a Homero y Virgilio]". No disiento de ninguno de los tres estudiosos, pero este tipo de comentarios no explica el fenómeno, particularmente novohispano, de los centones gongorinos; todos, además, dedicados al mismo tema, la Inmaculada Concepción. Como Virgilio fue el sostén de parte de la épica guadalupana (en algunos de los centones latinos), el conceptismo y la lírica gongorinos lo fueron de materia tan difícilmente asible: no hay que dejar de lado que los seis centones son parte de certámenes dedicados al misterio mariano. La ecuación centón-Góngora-Inmaculada Concepción debe significar algo más que ejercicios o divertimentos sociales, académicos o literarios.

Como se sabe, la Inmaculada Concepción fue declarada dogma en 1854 por Pío IX, con la publicación de la bula Ineffabilis Deus, el 8 de diciembre de ese año. Pero la disputa teológica 
data del siglo XIII. El bando "anticoncepcionista" (representado por santo Tomás de Aquino) sostiene que, como todo mortal, María fue concebida en pecado original. Santo Tomás tocó tangencialmente el tema de la Inmaculada Concepción al tratar la impecabilidad de Cristo: "Si María hubiera sido concebida sin pecado original, no habría sido redimida por Cristo y, por tanto, éste no sería el Redentor universal de los hombres, lo cual disminuye su dignidad" (Comp. Theologiae, p. 1, c. 224; apud Ros 1994, p. 149). El bando "concepcionista" (comandado por Duns Escoto) supone que María fue exceptuada, sólo ella, del pecado original. Escoto trató de demostrar que la Inmaculada no excluye la idea de la universalidad del pecado ni de la redención de Cristo: "La concepción y la animación son simultáneas. María, santificada desde el primer instante de su concepción, fue redimida (se salva así la universalidad de la redención de Cristo), no con redención restauradora o liberativa, propia de todos los mortales, sino con redención preservativa" (id.).

La monarquía hispánica vivió con especial intensidad y significado el inmaculismo, pues desde el siglo xv el catolicismo hispánico "ligaba la evolución de la propia religión a la definición de la Monarquía y de sus sociedades" (Ruiz Ibáñez y Sabatini 2019, p. 13) ${ }^{16}$. Con todo,

El éxito del inmaculismo y su imbricación medular en la sociedad, no puede explicarse solo por la existencia de una voluntad política o por la disponibilidad de unos canales de difusión eficaces, sino que se debió a que la Monarquía y sus sociedades pudieron explicar a través de ella cómo se veían y cómo querían llegar a ser. La maleabilidad con la que se podía significar políticamente una adhesión a la Pura Concepción, las consecuencias sociales de ponerse bajo su ejemplo y patronazgo, y su utilización como metáfora para pensar una Monarquía que se colocaba bajo su protección resultó lo suficientemente potente como para que pudiera atravesar reinados y dinastías, llegar a los palacios y movilizar a las gentes ordinarias. La Inmaculada se declinó políticamente de múltiples formas y en múltiples espacios, y siempre para dignificarlos y para hacerles partícipes del honor que suponía haber tomado como bandera a la Madre de Dios en su advocación inmaculada (p. 16).

16 Agradezco a Amelia de Paz la noticia de la publicación de este trabajo, que salió apenas en septiembre de 2019, y del cual no tenía noticia. 
Como en toda sede católica, en Nueva España se vivía esa misma discusión. Los dominicos representaban el ala "anticoncepcionista", y los franciscanos con los jesuitas, el ala "concepcionista”. Esto es, la Inmaculada era sólo una doctrina en el siglo XVII, no un dogma; se valía aceptarla o rechazarla. Sin embargo, en el mundo hispánico-católico tuvo una efervescencia muy particular, no sólo en la discusión teológica (y/o política) de las altas esferas eclesiásticas y civiles, sino en toda la comunidad: "las controversias sobre la Inmaculada llegaron a revestir formas de histeria colectiva"17. Como bien señala Carlos Ros (1994, p. 13): "Fue el pueblo, esencialmente el pueblo, el que empujaba hacia adelante en su devoción de la Virgen María en su concepción inmaculada y el que obligaba a los teólogos a buscar vías de comprensión teológica de este misterio".

Según explica Francisco Montes González (2016, pp. 209216), la dinastía de los Austrias y el clero peninsular sumaron esfuerzos para difundir el culto a la Inmaculada Concepción. El primero fue Felipe III ${ }^{18}$, en 1616, quien llegó hasta la Santa Sede con la argumentación para que la doctrina se elevara a dogma; lo único que logró fue la promulgación de la bula Sacratissimus Dominus noster, en la que Paulo V condenaba cualquier cosa que fuera contra la doctrina ${ }^{19}$. Los siguientes Austrias

17 Domínguez Ortiz, "Iglesia institucional y religiosidad popular en la España barroca”, apud Martínez Medina 2019, p. 53.

18 "Apenas cumplió el Arzobispo con el decreto del Tridentino y Bula de su Santidad... escribió el Señor Phelipe Tercero, haciéndole cargo, de que en su tiempo se había descubierto la más segura noticia de la Concepción, tan deseada antes por la Iglesia, ya tan necesaria en tiempo, en que en las demás provincias se había controvertido; y que, pues Dios la puso en su mano en la provincia de España, era su voluntad (al parecer) manifestar la elección del Rey católico, y a los españoles para defensores de su inmunidad; y que así debía interponerse su Cathólico zelo con su Santidad..." (Serna Cantoral, Vindicias Cathólicas Granatenses. Relación breve de las reliquias que se hallaron en la ciudad de Granada en una torre antiquísima y en las cavernas del monte illipulitano de Valparayso [sic] cerca de la ciudad; sacado del proceso y averiguaciones, que cerca de ello se hizieron, Lyon, 1706, apud MARTínez MEdina 2019, p. 46).

19 De hecho, a fines del año de 1618, los plateros de la ciudad de México convocaron a un certamen para celebrar "los favorables decretos que nuestro muy santo Padre Paulo V concedió a la limpieça de la Reyna de los Ángeles" (Archivo General de la Nación, ramo Inquisición, vol. 485, exp. 1, s.f.). Los "favorables decretos" se refieren a que un año después, en 1617, el papa hizo explícita prohibición de enseñar la sentencia antiinmaculista (la prohibición incluía también las simples conversaciones): nadie podía 
continuaron con la campaña proinmaculista, sin éxito alguno. Finalmente, en 1661, Alejandro VII promulgó la bula Sollicitudo omnium ecclesiarum (el 8 de diciembre, día en que se celebra actualmente esta fiesta mariana). Tras esta bula, todo parecía estar listo para la sentencia, es decir, la definición dogmática; pero Alejandro VII no llegó a tanto.

El conflicto político entre los reyes de España y el papado repercutió en Nueva España. Como en el resto del mundo católico, las diferentes órdenes religiosas se alinearon en favor y en contra, pero también se vieron involucradas otras instituciones, principalmente la Universidad ${ }^{20}$. El 26 de agosto de 1652, los franciscanos convocaron a una reunión en la que decretaron que la comunidad de San Francisco se encargara todos los años de celebrar la fiesta con misa y sermón en la Universidad y, además, "votar el misterio con diversos actos públicos": procesión solemne, altares, sermones panegíricos, certámenes poéticos, comedias, mascaradas, toros, etcétera (Montes González 2016, p. 210).

decir pública o privadamente que la Virgen había sido concebida con el pecado original. Como parte de los festejos, los organizadores elaboraron (y dedicaron a la catedral) una imagen de la Virgen en plata pura y virgen, de vara y medio de alto; y, el viernes 9 de diciembre de 1618, salieron los plateros a caballo, acompañados por la nobleza de la ciudad, a publicar una justa poética. El certamen, finalmente, no se llevó a cabo, pues durante el octavario de la fiesta, dominicos, por un lado, franciscanos y jesuitas, por otro, se dedicaron a insultarse, usando como dardos las homilías. Pero esto sucedía a principios del siglo XVII; para finales de este mismo siglo, la doctrina inmaculista ya no era materia de debate, sino de celebración. Cf. Tenorio 2010, pp. 319-321.

${ }^{20}$ Curiosamente, a uno y otro lado del Atlántico, aparte de las órdenes religiosas, fueron las universidades las más activas promotoras del voto inmaculista. Particularmente en relación con las universidades de los virreinatos, explica el R.P. Severino de Santa Teresa (1954, p. 217) que éstas "venían a ser como el corazón y eje de afirmación concepcionista" y que "en todos estos centros universitarios se cumplía rigurosamente lo que las leyes de Indias prescribían sobre el voto concepcionista a los profesores y graduandos". Entre las obligaciones de los universitarios, estaban "que los catedráticos enseñen el misterio de la limpia Concepción de Nuestra Señora" y "que el que se hubiese de graduar jure la opinión pía de Nuestra Señora estando jurada por la Universidad" $(i d$.$) . De hecho, la Real y Ponti-$ ficia Universidad de México estaba consagrada a la Inmaculada Concepción: "En el retablo de su capilla estaba el estandarte que llevó a la conquista Hernán Cortés con una hermosísima imagen de Nuestra Señora coronada de oro con doce estrellas también de oro y con las manos juntas, en forma algo parecida a la imagen que había de aparecer luego en Guadalupe" (p. 218). 
Escribe Carlos Ros (1994, p. 148) que "el pueblo no sabe de sutilezas escolásticas". La dificultad teológica del misterio es patente: ¿cómo compaginar la universalidad del pecado original, tan propugnada por san Pablo en sus cartas, y la redención de Jesucristo para toda criatura, con la concepción sin mancha de María? Muy difícilmente; por algo el dogma se promulgó hasta el siglo XIX ${ }^{21}$. Prescindiendo de cuestiones políticas y diplomáticas (España como el imperio campeón en la defensa del catolicismo frente a la Iglesia protestante) y teológico-políticas (las pugnas entre las diferentes órdenes religiosas, que no sólo obedecían a diferencias doctrinales), el tema de la Inmaculada Concepción tuvo gran importancia como motor del ingenio novohispano; por su indefinición y fragilidad teológicas, exigió a los poetas un trabajo alegórico y verbal digno de atención; de ahí los centones gongorinos.

\section{Agustín de Salazar y Torres:}

\section{LA VISIÓN DEL APOCALIPSIS}

Al parecer, cronológicamente, el primer centón gongorino compuesto en Nueva España es el de Agustín de Salazar y Torres (1636-1675), poeta nacido en Soria, que llegó a Nueva España a los 9 años. Muy tempranamente empezaron a imprimirse sus primeras composiciones: en 1653, cuando tenía 17 años, publicó la Descripción en verso castellano de la entrada pública en México del Sr. Duque de Alburquerque, su virrey (México, 1653); poco después entró a trabajar a la corte del virrey. Dice Francisco Montes González (2016, p. 211) que, a su llegada a Nueva España, el duque de Alburquerque trajo una real cédula de Felipe IV “con el mandamiento de que las órdenes militares y los tribunales de aquel reino jurasen defender" la concepción sin mancha de la Virgen María -de hecho, la entrada oficial del virrey fue el 15 de agosto, día que se celebra la otra gran fiesta mariana: la Asunción ${ }^{22}$. Según Montes González, no habría mejor embajador para la promoción del misterio mariano, pues el duque era

21 Según Martínez Puche (2004, p. 109), las definiciones dogmáticas marianas sirven de contrapeso al "enorme déficit de feminidad que aqueja al dogma cristiano en general”. ¿Será?

22 "Viernes 15 de agosto, día de la Asunción de nuestra Señora, a las seis horas de la tarde, entró en público el duque de Alburquerque, habiendo estado diez días en Chapultepec" (Guijo 1953, t. 1, p. 224). 
inmaculista de linaje: "sus ascendientes protagonizaron algunas de las embajadas que habían defendido el misterio ante el papado" $(i d$.$) .$

La entrada de Guijo del 5 de octubre de 1653, correspondiente a la relación del "Juramento de defender la Concepción de nuestra Señora”, ocupa tres páginas completas: el virrey trajo la orden desde España; reunió a "militares y tribunales" en la iglesia del convento de San Francisco -recordemos que los franciscanos eran de los principales promotores del voto concepcionista- para que juraran el voto; mandó que se decorara profusamente el templo; de esta decoración destaca la "representación" montada en el sagrario: "fingiendo en el Sagrario un trono y por remate un bosque de nubes, un bulto de la Soberana Reina de los Ángeles que la cercaban, y sobre su cabeza medio cuerpo de hombre, armada con una espada en la diestra y una palma en la siniestra, y rompiéndose la celada de un lado y otro, le servía de rostro el Santísimo Sacramento" (Guijo 1953, t. 1, p. 233; nótese la cantidad de elementos icónicos, voceros mudos, altamente significativos para el imaginario simbólico de una comunidad como la novohispana). Junto a esta estatua de la Virgen, se colocaron las de san Pedro Nolasco, san Pedro Apóstol, san Agustín y san Ignacio, y, según relata Guijo, cada una de las órdenes religiosas mandó una escultura de su patrón, excepto los dominicos, cosa que el diarista sólo menciona como de paso: "y los padres dominicos no tuvieron lugar de enviar al glorioso santo Domingo" (p. 234). Igualmente, se dispuso un tablado para los virreyes y su cortejo, "y allí almorzaban y bebían chocolate a costa de los frailes franciscos" ( $i d$.). Había octava y cada día predicaba un miembro de las diversas órdenes religiosas. En medio de todo este boato, se hacía el juramento:

La forma del juramento que cada tribunal hacía era diferente, mas una en sustancia; hacíase después de dicho el Evangelio que bajaban el preste y ministros, y se sentaban cerca de la mesa, y un secretario del tribunal o escribano le leía, y luego se levantaban de dos en dos los que le hacían y se hincaban de rodillas delante de la mesa, y ponían la mano derecha en el misal y cruz y se volvían al lugar que les cabía, y luego subía el predicador al púlpito y predicaba el misterio y explicaba el juramento (pp. 234-235).

Todo este aparato da cuenta de lo que la Inmaculada Concepción significó, más que teológica o religiosamente, como 
herramienta de cohesión política (civil o eclesiástica), ideológica y cultural.

Finalmente, el lunes 29 de diciembre, la Universidad convocó al certamen en honor a la Inmaculada, que se realizaría el 18 de enero del año siguiente. Antes hubo, según Montes González (2016, p. 215), otros dos "eventos literarios".

Es muy probable que el centón de Salazar y Torres haya formado parte de alguno de esos dos performances anteriores a la publicación del certamen de la Universidad, en el cual también participó con un romance "de equívocos" y unas redondillas de pie quebrado (segundo y primer lugares, respectivamente: Certamen poético 1654, s.f.). En todo caso, está recogido en su Cítara de Apolo (Madrid, 1681 y 1694). La génesis de un centón gongorino, en el caso de Salazar y Torres, no está sólo en el requerimiento de algún certamen (como lo aclara el epígrafe: "Fue asunto de un certamen de la Purísima Concepción de Nuestra Señora"), sino en la anécdota que cuenta su editor, Juan de Vera Tassis:

...en aquel sabio colegio de la Compañía de Jesús, teniendo aún menos de doce años de edad [en realidad, 18], después de haber recitado las Soledades y Polifemo de nuestro culto conceptuoso cordobés, fue comentando los más obscuros lugares, desatando las más intrincadas dudas y respondiendo a los más sutiles argumentos que le proponían los que muchos años se habían ejercitado en su inteligencia y lectura (Salazar y Torres 1694, f. 4r-4v; modernizo ortografía).

Esto es: la ocurrencia le cayó a Salazar como anillo al dedo, pues ya se sabía de memoria la obra de Góngora.

El epígrafe dice: "Describe la visión del capítulo doce del Apocalipsis, con sólo versos mayores de don Luis de Góngora, siguiendo el método de las Soledades" (Salazar y Torres 1694, p. 259). La teología mariana ha usado como fundamento para documentar los dogmas de la Inmaculada y de la Asunción la visión de san Juan en el capítulo 12 del Apocalipsis. El "método de las Soledades" alude, simplemente, al metro: la silva. Góngora, pues, no sólo aporta los versos, sino también el molde métrico.

No sabemos en qué certamen se presentó este centón, ni cuáles eran los requerimientos de las diferentes secciones; por tanto, no podemos saber si se explicitaron, como sucede en la Empresa métrica y en el Triunfo parténico, las normas centonarias 
que se aplicarían (por ejemplo, si se valían dos versos seguidos o añadir uno que otro verso propio para ligar los ajenos); tampoco sabemos si se pidió a los autores consignar al margen la procedencia de los versos (como se verá más adelante; en el Triunfo parténico incluso se regula la edición de las obras de Góngora que deben usar los poetas). Conocemos el centón tal como se reproduce en la Cítara de Apolo, publicada casi treinta años después por Juan de Vera Tassis, de quien sabemos que metió mano en las obras de su amigo. Así, pues, con las reservas del caso, haré un breve análisis del centón.

A pesar de lo dicho en el epígrafe, además del modelo confesado (las Soledades), por el centón corre el espíritu y el aliento de otra composición gongorina, el Panegírico al duque de Lerma. El poema comienza con un apóstrofe (de 13 versos) a la Musa, pidiéndole inspiración. No es casual que los dos primeros versos correspondan a los dos primeros del Panegírico. En las composiciones centonarias, la originalidad está en la elección de los versos y en el acomodo que se les da; esas solas dos decisiones ya son un gesto retórico, cuyo significado no se nos debe escapar²: "Si arrebatado merecí algún día / tu dictamen, Euterpe, soberano...”. Según la Teogonía de Hesíodo, Euterpe es la musa de la flauta; por extensión, de la poesía bucólica. Muy deliberadamente Góngora invoca a esta musa pastoril como inspiración de su poema más convencionalmente épico (las hazañas del duque de Lerma, un grande de España, relatadas en octavas reales, el metro épico por antonomasia). De esta manera, el cordobés reconfigura el tópico y hace a Euterpe patrona de la poesía épica, elevada, sublime. Es el mismo aliento que recupera Salazar y Torres: una épica a lo divino que legitima el misterio de la Inmaculada. El resto de estos primeros trece versos incluye los tópicos convencionales de este tipo de invocaciones: la falsa modestia y la promesa de fama universal:

Si, arrebatado, merecí algún día tu dictamen, Euterpe, soberano, solicitando en vano las alas sepultar de mi osadía,

23 "I have tried to bring allusion and poetic memory (within which I situate allusion) into a functional rhetorical matrix (defining rhetoric as the ability to motivate the linguistic sign) and thus to make them contribute to the process of poetic signification as constitutive elements of poetic discourse" (CONTE 1986, p. 23). 
audaz mi pensamiento

su canoro dará dulce instrumento,

son de la ninfa un tiempo, ahora caña, si ya la erudición no nos engaña ${ }^{24}$ :

émula de las trompas su armonía,

el séptimo Trïón de nieves cano;

el rico de rüinas Océano;

la adusta Libia sorda aún más lo sienta

que los áspides fríos que alimenta (vv. 1-13).

Aunque aparentemente en el centón se reciclen versos gongorinos en formas que no tienen nada que ver con su contexto original, en realidad el poeta centonista está muy consciente de la procedencia de esos versos, por lo que como lectores debemos estar muy alertas de que no todas las "suturas" son ocurrencias casuales, sino que en muchas ocasiones el sentido del pasaje está en el vínculo significativo que se establece con el modelo ${ }^{25}$. De ahí la importancia de señalar la procedencia de los versos ${ }^{26}$, como ya dije, una de las pocas decisiones en

${ }^{24}$ El verso está recompuesto; la cita no es textual: "no es sordo el mar (la erudición engaña)”. Uso la siguiente edición: GóngORA 2000.

${ }^{25}$ STEPhen Hinds (2014, pp. 176-177) hace un análisis muy sugerente de la relación entre los versos del centón de Proba y su original virgiliano. Pone como ejemplo el pasaje del Génesis en que Dios instruye a Adán y a Eva sobre cómo comportarse en el Paraíso (vv. 139-144 del centón de Proba). Los versos provienen, en su mayoría, de la Eneida: "vivite felices * interque nitentia culta / fortunatorum nemorum sedesque beatas, / haec domus, haec patria est, * requies ea certa laborum. / His ego nec metas reum nec tempora pono: / imperium sine fine dei, * multosque per annos / non rastros patietur humus, non vinea falcem" (los asteriscos marcan que se usaron hemistiquios, no versos completos). "How can a resourceful poet «patch» together the Garden of Eden, before the Fall of Man, with lines and half-lines from Virgil. Well (line 140 [«fortunatorum nemorum sedesque beatas», Eneida, VI, v. 639]), on the principle that the closest Virgilian approach to the Christian paradise will be found in a pagan paradise, she [Proba] should first select a segment of the Elysian field from Aeneid 6. Then (line 141 [«hic domus, haec patria est», Eneida, VII, v. 122]), to sustain the sense of an idealized God-given enviroment, she should add a visionary glimpse of Italy as promised land, both in the achievement (Aeneid 7) and in the promise (Aeneid 3); and she should follow up immediately (142-3 [«His ego nec metas rerum nec tempora pono: / imperium sine fine dedi», Eneida, I, vv. 278-279]) by taking over some words from the divine promise of Roma aeterna back in Aneid 1". (Uso la edición de Virgilio 2003).

${ }^{26}$ Independientemente de la buena o mala memoria poética del lector, dar a conocer explícitamente la procedencia de los versos es fundamen- 
que el poeta ejerce su libertad creativa: los versos 1-2, 9-10 y 12-13 vienen del Panegírico; 3-4, 6-8, de las Soledades; y el 11 de la canción "De la armada que fue a Inglaterra" (nótese el tema). Como se ve, esta breve introducción abre y cierra con versos del Panegírico, tomados, además, de su primera parte, con la que se corresponde, en cuanto a funciones narrativas y retóricas. Los "retazos" están zurcidos con cierta fortuna; en buena medida porque Salazar y Torres usó pares y no versos sueltos, con lo que parte de la coherencia, tanto sintáctica como semántica, se resuelve, pues estaba resuelta en el original ${ }^{27}$.

El capítulo 12 del Apocalipsis está dividido en tres secciones: "El mesías y el dragón", "La batalla en el cielo" y "El dragón persigue a la mujer". Señala Ponce Cárdenas, creo que acertadamente, que, prescindiendo de los primeros trece versos (que son como la introducción), el centón también se divide en tres partes, siguiendo la división bíblica. Lo primero que relata el pasaje bíblico es la aparición de la mujer: "Y apareció en el cielo una señal grande, una mujer envuelta en el sol, con la luna debajo sus pies, y sobre la cabeza una corona de doce estrellas" (12:1). Así, del verso 14 al 62, Salazar compone el retrato de la Virgen, un retrato que mezcla la iconografía apocalíptica con los tópicos petrarquistas; por un lado, desfilan los soles, el oro, la nieve, las flores de abril, el nácar, para describir la belleza de la mujer aparecida; por otro, con ingenio, el poeta va trabando versos que aluden a la representación de la Inmaculada: "Ciñió sus sienes bellas / de antárticas estrellas" (vv. 24-25), o "en hombros, pues, querúbicos, María, / deidad resplandeciente” (vv. 48-49). Particularmente logrado me pare-

tal, pues esas referencias son el "santo y seña", las instrucciones de lectura, el mapa que guía tanto al autor cuanto al lector. De hecho, según señala G.H. Tucker (2013, p. 155), todos los centones renacentistas se publicaban poniendo al margen las referencias de los versos (como sucede en la Empresa métrica y en el Triunfo parténico).

27 Usar versos seguidos es una práctica que Ausonio reprobaba, pero no es el único truco al que recurren los poetas centonarios, de Proba en adelante: "Rispetto alle rigide regole ausoniane emergevano cosí licenze di vario tipo, dalla ripetizione di versi all'uso di segmenti più brevi di un emistichio, dalle anomalie metriche e prosodiche alle imprecisioni sintattiche, dalle oscurità di censo alle vere o proprie modificazioni del testo centonato, che vanno dal piccolo ritocco ad una desinenza, per dare al nuovo verso un andamento grammaticale corretto, alla totale sostituzione di una parola" (Polara 1990, p. 261). Los poetas centonistas novohispanos se tomaron varias de esta licencias. 
ce el pasaje en que el diablo acecha a la Virgen. Después del versículo citado, la primera parte del relato bíblico cuenta que la mujer está a punto de parir, pero aparece un dragón que quiere tragarse al hijo en cuanto nazca. Así lo relata Salazar con modulaciones gongóricas:

En hombros, pues, querúbicos, María,
deidad resplandeciente,
levanta aquel León fiero
del tribu ${ }^{28}$ de Judá, que honró el Madero:
donde al pie de la Virgen una a una
hueste alada son cercos de la luna,
cuyos altos no le era concedido
al serafín pisar, más levantado,
envidioso aun antes que vencido,
en bordadura pretendió tan bella
poco rubí ser más que mucha estrella,
y, cuando no admirado,
se esconde, cual serpiente
en roja sangre y en ponzoña fría,
pisando la dudosa luz del día (vv. 48-62).

El León fiero es Cristo, como se aclara en el verso siguiente. En Apocalipsis 12:3-4, se dice que la mujer parió un varón "que ha de apacentar a todas las naciones con vara de hierro"; es decir, el Salvador que venció el mal y redimió a la humanidad. Ahí están prefigurados el envidioso dragón (demonio) que se atreve a desafiar y la Virgen. Quizá la fortuna del pasaje se deba a que Salazar introduce varios versos propios como puentes (los vv. 48, 52-54, 56 y 61), con lo que la congruencia semántica y sintáctica queda asegurada.

Además de los seis versos ya señalados, en esta primera parte hay otros tres versos de Salazar; de los 39 restantes, no es de extrañar (porque el tema es, finalmente, un retrato femenino), 15 provienen de los sonetos amorosos de la etapa "petrarquista" de Góngora; incluso figura entero el primer cuarteto del soneto "De pura honestidad templo sagrado..." (vv. 38-41: cuatro versos

28 "del tribu": el Dicc. Aut. (s.v.) da este sustantivo como femenino o masculino, indistintamente. En uno de los pasajes citados en el mismo Diccionario se usa como masculino: "Escritores árabes dixeron fabulosamente que Mahoma era del tribu de los sarracenos"; en el otro, en plural, como femenino: "Después de un cautiverio tan prolixo, / sacó las tribus y llamó a su hijo". 
seguidos. ¿Qué diría Ausonio!); 15 están tomados de la Soledad I, los quince relacionados con descripciones femeninas y, de alguna manera, recreaciones de la tópica petrarquista; de los otros nueve, tres son de las octavas a san Ildefonso, cuatro del romance "Moriste, ninfa bella" (heptasílabo, por eso puede usarse), uno de la Comedia venatoria y uno del Polifemo. Como puede verse, no se trata de amontonar versos sin ton ni son; el sentido dicta el "factor de preferencia" (como lo llama José Luis Vidal 1973, p. 54), esto es, qué versos y de dónde se toman.

La segunda parte del centón (vv. 63-74), como la de Apocalipsis 12:7-8, relata la batalla entre el cielo y el dragón: "Y hubo una batalla en el cielo: Miguel y sus ángeles peleaban con el dragón, y peleó el dragón y sus ángeles, y no pudieron triunfar ni fue hallado su lugar en el cielo". Salazar nuevamente se valió, en buena medida, de composiciones de corte amoroso, haciendo el paralelo entre el amor y sus efectos (dolor, celos, engaño) y el dragón o víbora, pues no son pocas las representaciones del amor como "ponzoñosa víbora" escondida entre las flores:

Tarde batiste la envidiosa pluma, de cuyo vuelo osado observarán su desvanecimiento los anales diáfanos del viento. ¡Oh ponzoñosa víbora escondida de verde prado en oloroso seno, esfinge bachillera y sierpe, al fin, pisada! ¡Oh pájaro de averno, mayor debes de ser que el mismo infierno! Pues comes de ti mismo y no te acabas, vuélvete al lugar triste donde estabas (vv. 63-74).

La mitad de los versos (6) proceden de sonetos amorosos, tres de la Soledad II, uno de la Soledad I, uno de la canción "QQué de invidiosos montes!" (amorosa) y uno de otra canción, "Moriste en plumas no, en prudencia cano". Tan atinado es el factor de preferencia que Salazar no se ve en la necesitad de meter versos sueltos: logra tejer los gongorinos de manera no sólo muy coherente, sino elocuente. La preferencia se debe a que en las composiciones amorosas es usual que el acecho y el peligro del amor se representen como una serpiente escondida y lista para tirar su veneno. Aprovecha especialmente el 
soneto “;Oh niebla del estado más sereno!”, terrible representación de los celos como "furia infernal", "serpiente mal nacida" (esta vez no usa los versos seguidos). Es apenas un pasito el que hay que dar para que el diablo venga a ser esa "furia" o "serpiente" que aguarda con astucia y cautela: es el demonio el que está al acecho y pronto para esparcir su mal. Sólo un verso, pero muy bien escogido, proviene de la Soledad I (v. 114): "esfinge bachillera”. En Góngora, el verso aparece en el parlamento “;Oh bienaventurado albergue!”, en el que se van presentando, apoyados en su representación emblemática, cada uno de los vicios de la corte. Esa "esfinge" que miente desde su apariencia misma, pues comienza con rostro humano y termina en animal, y además "bachillera", habladora, tentadoramente elocuente, es una muy convincente imagen de las tentaciones del demonio, de aquella tentación primigenia (el demonio como serpiente seduciendo, "bachilleramente" -es decir, con "palabras bonitas"-, a Eva) que propició el pecado original. Los vv. 65-66 vienen de la Soledad II, vv. 142-143; también la "sierpe, al fin pisada" (v. 320), perfecta si recordamos la representación de la Virgen pisando la serpiente. Finalmente, los vv. 63 y 71 vienen motivados, el primero, por "la envidiosa pluma", y el segundo, por el término Averno ${ }^{29}$.

Los últimos versos, ya independientes de la estructura bíblica, narran el triunfo de la Virgen sobre el demonio, su exención del pecado original. María, la "blanca Aurora" (del soneto "Raya, dorado sol, orna y colora"), Aurora que "crepúsculos [sombras, manchas] ignora" ("Tres violas del cielo", v. 6): "tu cerviz pisa dura, / yugo te pone de cristal, calzada / coturnos de oro el pie, armiños vestida" (vv. 77-79). Afortunadísima traslación; sin embargo, algo tramposa, pues los tres versos, en ese mismo orden, se toman de un solo soneto, "Montaña inaccesible, opuesta en vano". Otra vez los sonetos predominan como surtidores de versos, aunque hay algo más de variedad: las dos Soledades, la Égloga piscatoria, las octavas a san Ildefonso y a san Francisco de Borja. Para cerrar elegante y congruentemente el centón, Salazar y Torres compone ad hoc los cinco versos finales:

29 Dice G.H. Tucker (2013) que varias veces, en sus centones, el ya mencionado Lelio Capilupi junta los versos a partir de la coincidencia de elementos verbales comunes: "In such instances it is as if the verbal coincidence between two otherwise disparate verses is triggering the combination of fragments he is employing" (p. 171). 
ilustre y hermosísima María, templo de quien el Sol aun no es estrella, aun a pesar de las tinieblas bella, aun a pesar de las estrellas clara, hoy de Moisés la vara* los márgenes matiza de las fuentes, serafines volantes y obedientes, * en quien la Virgen estampó sus huellas, * llegad al cielo vuestras sacras frentes, ${ }^{*}$ que, eternizadas en sus luces bellas, * estampas usurpáis a las estrellas*30 (vv. 83-93).

\section{LOS CENTONES DE EMPRESA MÉTRICA}

El certamen Empresa métrica (México, 1665) fue una "Vesta mejor", porque ella no pide para sí las ofrendas, sino para Jesús, con quien está "obligada" por el privilegio concedido (la exención del pecado original). A la propuesta alegórica hay que añadir la anécdota histórica: el templo terminó de construirse mucho tiempo después con el muy simbólico gesto de llevar una imagen de Jesús Nazareno.

Para tratar este asunto, se propusieron tres metros: una glosa, diez "quintillas facetas" y una silva (mismo metro de las Soledades) de centones de versos "del Píndaro más lírico don Luis de Góngora” (f. 15r). En este caso sí sabemos que el secretario prescribió: "no valiéndose de los de arte menor, ni de los sagrados, ni de más de dos seguidos" (id.). Igualmente, se exigió anotar a los márgenes las referencias de los versos, sin sugerir ninguna edición en particular. En la sección de centones obtuvieron primer lugar: Juan de Guevara, Alonso Ramírez de Vargas y Félix López Muñiz -parecería que era tan difícil juzgar el mérito o el logro de los centones, que los jueces se decantaron por un triple empate en primer lugar.

Las tres composiciones son, lógicamente, muy parecidas, y muy similar el factor de preferencia (por obvias razones; por ejemplo, el primer verso del soneto "Ilustre y hermosísima María", usado también por Salazar y Torres, figura en dos de los tres centones); con todo, el trabajo no es exactamente el mismo. Veamos cómo decide comenzar cada poeta. Juan de Guevara:

${ }^{30}$ Los versos con asterisco son de Salazar y Torres. 
Si arrebatado merecí algún día

de las Ninfas el coro y su concento,

émula de las trompas su armonía,

su canoro dará dulce instrumento,

cuando la Fama no, su trompa al viento (vv. 1-5).

Estos primeros cinco versos constituyen la tópica petición de inspiración. Pueden parafrasearse así: "Si, estando arrebatado [por la inspiración], algún día merecí el coro y el concento de las Ninfas, cuya armonía es émula de las trompas [trompetas de la Fama], ese coro [me] dará su dulce canoro instrumento, si no es que la Fama [dará] su trompa al viento". Los cinco versos proceden de dedicatorias gongorinas: los w. 1 y 3 , de la del Panegírico; el resto, de la de las Soledades. No hubo, pues, que hacer un gran trabajo de reconfiguración o recontextualización: orgánicamente, en el modelo, los versos estaban dispuestos para cumplir la misma función de apertura-homenaje que en el centón.

Alonso Ramírez de Vargas:

Cuantos me dictó versos dulce Musa, en soledad confusa, escucha al son de la zampoña mía, ilustre y hermosísima María, bellos efectos, pues la causa es bella. Alterna con las Musas hoy el gusto, por que Talía mejor los triunfos cante* en cítara sonante;* que si la mía puede ofrecer tanto, siendo tuya la voz y el canto de ella, dulzuras acrecientan a dulzuras (vv. 1-11).

Algunos de estos versos provienen, como en el caso de Guevara, de pasajes inaugurales: vv. 1-2 del comienzo de las Soledades; 3 , 6 y 9 , de la dedicatoria del Polifemo. Aquí, el oficio de Ramírez de Vargas está en haber tomado versos de contextos muy disímiles (no como Juan de Guevara, que aseguró la congruencia tomándolos de pasajes con la misma función retórica). Los vv. 4, 5 y 10 proceden de sonetos; el 11, de la canción "Por este culto bien nacido prado..."; 7-8 son apócrifos. Me explico: no los compuso Ramírez de Vargas para la ocasión (como hizo Salazar y Torres), sino que los tomó de unas octavas ("Yaze a la parte del templado") que figuran como de Góngora en la edición de 
Gonzalo de Hoces (1654, ff. 141v-144v), aunque modernamente se ha descartado tal atribución. Los versos en cuestión son los dos últimos: "Por que Talía mejor los triunfos cante / de la fe sacra en cítara sonante". Ramírez de Vargas cometió tres infracciones: tomó dos versos seguidos de una composición religiosa y alteró el segundo.

Este comienzo resulta mucho más enfático que el de Guevara, pues la apostrofada es la propia Virgen María, la "ilustre y hermosísima María”. Ramírez de Vargas no sólo amontona los versos gongorinos: los acomoda con oficio, cargándolos de nuevos sentidos, e incluso logra fraguar dos conceptos bastante sencillos, no con la complejidad de los de Góngora: el poeta pide a María que escuche los versos que le dictó la dulce Musa; versos que resultan hermosos no por el dictado de la Musa, sino porque es la Virgen la "causa bella" que los inspira. El segundo es el convencional tópico de la promesa de fama eterna, pero aquí "a lo divino": el poema resultará inmortal porque la voz (el contenido del canto) del poeta proviene de María, y el canto (la música, la forma) de Talía. El caso es que el modelo trasciende la mera función de proveedor de "retazos"; el quid de la estética gongorina (la construcción de conceptos) se cuela imperceptiblemente, llevado por los propios versos del cordobés, oficiosamente reconfigurados por el poeta novohispano.

Félix López Muñiz:

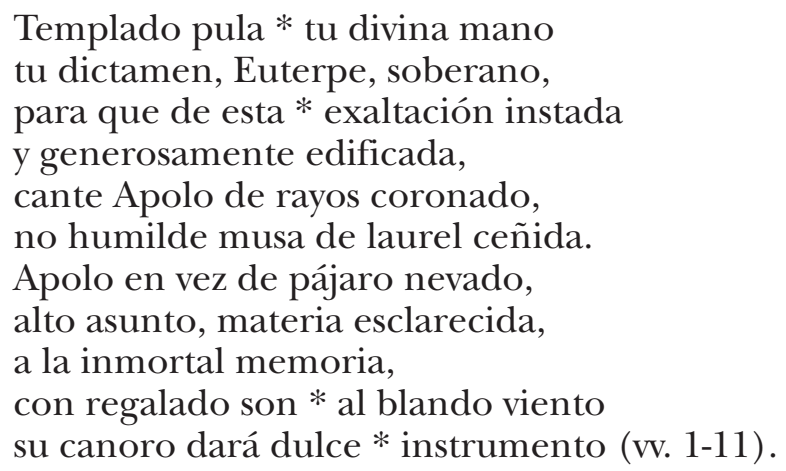

En tres ocasiones, López Muñiz toma hemistiquios en lugar de versos completos (vv. 1, 10 y 11), lo que no era una exigencia de esta sección del certamen. Es curioso el factor de preferencia, tratándose del apóstrofe a la Musa: seis versos (3-7 y 10, los 
dos hemistiquios) proceden de sonetos; sólo dos (el segundo hemistiquio del primer verso y el 2, en un pareado "tramposo", pues son seguidos en el original) del Panegírico (1 y 2); tres más de las dedicatorias del Polifemo y las Soledades. No sé qué tan deliberada sea la operación de "zurcido" de los dos primeros versos, pero es bastante ingeniosa ${ }^{31}$ : que el dictamen ("inspiración') soberano pula, templado (en función de predicativo), tu divina mano. En Góngora, la iunctura "templado pula" obedece al léxico especializado de la cetrería; en el centón, el dictamen (previamente preparado como un halcón para la caza, que eso significa templado) dispondrá armónicamente la mano de Euterpe para tocar el instrumento que cantará las glorias del nuevo templo, tema del certamen.

También hay diferencias en la manera de introducir el asunto. Guevara fragua la ecuación alegórica templo/ María, no sólo por la doble advocación de la nueva edificación (a Jesús Nazareno y a la Inmaculada Concepción), sino porque María albergó a Cristo, en cuanto que lo encarnó: "Fecunda Madre bella, / templo de quien el sol aun no es estrella" (vv. 6-7). Por ello, la descripción se presenta en dos "tramos".

En el primero, se describe a María, usando la tópica petrarquista, por lo que abundan los versos procedentes de los sonetos amorosos de Góngora:

Aljófar blanco sobre blancas rosas, ilustre y hermosísima María, juraré que lució más su guirnalda, término puesto al oro y a la nieve, que la que ilustra el cielo en luces nueve; las rubias trenzas y la vista bella, delante quien el Sol es una estrella, ondeábale el viento que corría: corona de diamante, honor del día, luces brillando aquél, éste, centellas... (vv. 13-22).

Guevara completa el retrato de la Virgen con varios versos tomados de la Soledad I, todos relacionados con la descriptio puellae.

31 "Yet a cento-text might also be pieced together less self-consciously by a more spontaneous process of mental quarring from the treasure-house of a memorised cannonical author" (TuCKer 2013, p. 152). 
En el segundo tramo se describe "arquitectónicamente" el templo, y la procedencia de los versos es mucho más variada. Vistos en esta nueva configuración, es pasmosa la cantidad de versos gongorinos que pueden referirse, sin hacerles, prácticamente, ninguna violencia, a algo construido: "sublime edificio", "fábrica escrupulosa, y aunque incierta, / siempre murada, pero siempre abierta" (vv. 44 y 49-50). Los dos últimos versos son los 79-80 de la Soledad II; Guevara hizo trampa, pero la trabazón es muy elocuente. Góngora se refiere a la red de pescar: hecha escrupulosamente, aunque es incierta (porque flota en el agua); sirve de muralla a los peces, aunque esté abierta. Así, el templo es una edificación ("fábrica") bien cuidada ("escrupulosa"), "murada"; construcción terminada, pero (y por fin) "abierta" al devoto. O bien el "De pura honestidad templo sagrado", primer verso de un soneto de retrato petrarquista, que en Góngora se refiere a una dama, y aquí literalmente al "templo", cuya construcción "borró designios, bosquejó modelos, / al cóncavo ajustando de los cielos" (vv. 67-68), pareado (otra trampa) procedente de la Soledad I (vv. 98-99), en donde se refiere al "bienaventurado albergue", o sea, a ese lugar arcádico habitado por la bondad, la sinceridad, etc. Es una insinuación muy sutil, pero ahí está: la asociación entre el "albergue bienaventurado", lugar del que -en el poema gongorino- quedan fuera la mentira, la soberbia, la envidia, la simulación, la ambición, etc., y el nuevo templo. Si aceptamos la propuesta de análisis de Hinds (2014), debemos reconocer que no se trata de usar a Góngora como un repertorio de frases descontextualizadas, sino que, a veces, el poeta centonario está consciente del contexto gongorino original, y apela a ese contexto para redondear el sentido del verso. Leído así, el "bienaventurado albergue" es la mejor caracterización de un templo, a donde se va en busca de cobijo, amparo, esperanza.

Como Guevara, Ramírez de Vargas prosigue con la descripción de María, recurriendo a los tópicos del retrato petrarquista, sin limitarse a los sonetos; emplea igualmente versos procedentes de canciones, las Soledades, el Polifemo. Lleva a cabo un trabajo agudo y creativo de selección, pues fragua una ingeniosa premisa alegórica, de acuerdo con la cual elige los versos. Esta premisa es la Virgen como Aurora llena de flores que anuncia la llegada del Sol (Cristo), como el templo de la Inmaculada recibe a Jesús Nazareno. La poesía áurea está llena de flores y auroras en relación con la belleza femenina, y la de Góngora, además 
de recrear esta tópica, abunda en imágenes sobre el fenómeno físico del amanecer: el tono rosado antes de que salga el sol, la paulatina aparición del brillo solar, la fragancia de las flores al amanecer, etc. ${ }^{32}$ Así que, por un lado, la tópica sirve para el retrato; por otro, el fenómeno físico de la aurora, que anuncia el sol y ofrece flores, transmite muy elocuentemente el misterio de la Encarnación y la doble advocación del templo:

Esta de flores * siempre gloriosa

fecunda Madre, * agradecidamente, ofrece alegre * al Dios omnipotente los blancos lilios que, de ciento en ciento, nos da la primavera; las frescas rosas que, ambicioso, el viento con pluma solicita lisonjera: que piden, con ser flores, soberanos favores al gran pastor de pueblos que enriquece, cuyo bello contacto puede hacerlas, sin concebir rocío, parir perlas... (vv. 23-34).

Por supuesto, el centón también incluye la descripción del templo, que confirma lo ya dicho sobre la ductibilidad de los versos de Góngora para cuestiones arquitectónicas, pero en el caso de Ramírez de Vargas, según la premisa alegórica de la Virgen/ Aurora que anuncia al Sol/ Cristo, los préstamos se encuentran ingeniosamente trabados con la doctrina de la Inmaculada Concepción, a cuya veneración está dedicado el nuevo templo:

De pura honestidad templo sagrado, majestüosamente levantado, de las oscuras aguas del Leteo ostentación gloriosa, alto trofeo, en la materia y en el artificio, de la imperial ciudad patrio edificio. Aquí la primavera ofrece flores que el cielo pinta de cien mil colores;

${ }^{32}$ Véanse, por ejemplo, los primeros versos del siguiente soneto de GónGORA: "Raya, dorado Sol, orna y colora / del alto monte la lozana cumbre; / sigue con agradable mansedumbre / el rojo paso de la blanca Aurora..." (1985, p. 122). 
flores que ilustra otra mejor Aurora, un Alba que crepúsculos ignora, que privilegia el cielo con diferencia tal, con gracia tanta... Esta en forma elegante, salamandra del sol, * ninguno siente contagio original * un solo instante (vv. 77-94).

María es un templo "de pura honestidad", que se levantó sobre las aguas del Leteo al vencer al demonio; es la Aurora, el Alba que ignora la oscuridad del crepúsculo (el pecado), privilegiada, "con gracia tal, con gracia tanta" (muy afortunada y melodiosa traslación a partir de un típico soneto petrarquista). Es María "salamandra del sol", porque, como la salamandra no puede ser quemada por el sol ${ }^{33}$, ella no puede ser contagiada por el mal, es decir, nació exenta del pecado original.

No podía faltar la referencia a la doble advocación del templo. Realmente, Ramírez de Vargas es hábil para sacar jugo (incluso miel) de los versos de Góngora. Como el peregrino de la Soledad I "halló hospitalidad donde halló nido" el ave de Júpiter (es decir, desde la cumbre de la montaña, donde anida el águila, alcanzó a ver la cabaña que le daría abrigo), Jesús Nazareno halló hospitalidad en el templo de María, y nido en su vientre:

Nido del Fénix de mayor belleza,

Templo de amor, Alcázar de nobleza.

En esta, pues, fiándose atractiva

flamante llama, * así pagó obediente*

su Madre el celo ardiente,*

agradecida, * cuanto generosa,

a la satisfacción se disponía:

Virgen tan bella, ¿qué hacer podía? (vv. 122-128).

33 Era creencia muy extendida que la salamandra era resistente al fuego: "Insecto mui parecido al lagarto, aunque más pequeño... Echada en el fuego parece que por su humedad, o su peso, le amortigua por algún espacio" (Dicc. Aut., s.v. salamandra). Según Plinio, se trata de un "animal con forma de lagarto, cubierto de estrellas, que no aparece sino con grandes lluvias y que deja de hacerlo con cielo sereno. Es este animal tan frío que con su contacto apaga el fuego como si fuera hielo" (Historia natural. Libros VII-XI, X, 86: 2003, p. 442). 
Es María el nido del Fénix de mayor belleza (Cristo); es ella quien, fiándose (y siendo atraída) por la flamante llama del amor de Cristo, pagó el amoroso favor, al aceptar encarnar a Cristo y al recibir al Nazareno en su templo. La técnica del centón permite alteraciones mínimas en los versos originales. Apoyado en esta licencia, Ramírez de Vargas modifica el v. 128, procedente de la Soledad I, "virgen tan bella, que hacer podría" (v. 783) ${ }^{34}$. De esta manera, resume toda la Gracia de la Virgen en la pregunta retórica, no exenta de moralización: “¿Qué otra cosa podía hacer una Virgen como ella?”

Por su parte, López Muñiz es más explícito en la ecuación alegórica templo/ María; la marca desde los primeros versos del centón: "esta exaltación instada / y generosamente edificada" (vv. 3-4), apelando al nuevo templo como lo hace el peregrino de las Soledades cuando llega frente a la cabaña de los cabreros. Como ese peregrino, náufrago, cansado, perdido, asustado, encuentra amparo en la humilde choza, así el católico se acoge al segurísimo refugio de la doble advocación del Hijo y la Madre: "Oh bienaventurado / albergue a cualquier hora, / del reino escudo, gloria del estado" (vv. 18-20; aunque es trampa usar dos versos seguidos, la iunctura con "escudo del reino" y "gloria del estado" es muy afortunada). A diferencia de Guevara y de Ramírez de Vargas, López Muñiz sustituye la descriptio puellae por la descripción del templo, mezclando la tópica femenina petrarquista con una descripción propiamente arquitectónica. Por ello, los versos proceden básicamente de las estancias del "¡Oh bienaventurado / albergue..." (vv. 94-135 de la Soledad I), donde, como ya dije, el peregrino (o el narrador lírico) alaba la majestad rústica de la vivienda de los pastores, la ausencia de los vicios de la corte (envidia, soberbia, disimulación, etc.) y la inocencia y bondad que en ella moran. El poeta salpica con uno que otro verso de los sonetos amorosos:

Templo de Pales, alqueria de Flora ${ }^{35}$, no moderno artificio, de la imperial ciudad patrio edificio

34 El podía por podría no es modificación de Ramírez de Vargas; así está en la edición de Hoces, que tuvo varias reimpresiones. En Góngora el verso se refiere a la pastora que está por casarse (por eso "virgen"), que es tan bella, "que hacer podría / tórrida la Noruega con dos soles [sus ojos]".

35 Como en el caso del verso 96 de la Soledad $I$, hay que hacer sinéresis en alqueria (no alquería), para que salga el endecasílabo. 
en que la arquitectura

para su hermosura,

jaspes calzada y pórfidos vestida,

si a más gloriosa Fénix construida ${ }^{36}$,

a la geometría se rebela,

al soberbio Aquilón * sin alas vuela... (vv. 21-29).

Aquí la estética del centón funciona muy efectivamente: los versos se leen en dos niveles, el del contexto gongorino original y el de la nueva composición con un tema absolutamente ajeno al de la fuente. Los niveles no se superponen uno a otro: se funden, y gracias a esta fusión el pasaje gana mucho en espesor semántico: como la choza de los cabreros, "templo de Pales, alqueria de Flora", el nuevo templo (no de Pales, sino de Jesús Nazareno), lleno de flores (alquería no de Flora, sino de María), es majestuoso (sin ser ostentoso) y es morada de virtudes y muralla contra los vicios:

No, pues, de otra manera, siempre glorioso, * saludó sus rayos...

soberana beldad, valor divino,

que dio espíritu al leño y vida al lino,

entre los lilios mora

de los aromas * que troncó el Aurora (vv. 34-41).

El "siempre glorioso" es el templo, y éste, María. Recordemos que el templo originalmente iba a estar dedicado a la Inmaculada, y que, ya terminado, recibió la imagen de Jesús Nazareno; por eso María "saluda los rayos" del Sol, es decir, de Cristo; es ella la "soberana beldad" que vive entre los lirios que tronchó la Aurora; es ella quien "dio espíritu al leño y vida al lino". La reconfiguración de este último verso es todo un hallazgo: procede de otro soneto tardío (1614), no petrarquista, y como en

${ }^{36}$ Curiosamente, este verso no procede de los sonetos amorosos, más o menos tempranos, sino del soneto funerario al túmulo de la reina doña Margarita (1611). Góngora se refiere al túmulo como "máquina funeral" construida para una Fénix más gloriosa, es decir, la reina muerta (con todo el simbolismo que conlleva el ave Fénix: que se inmola a sí misma y renace de sus cenizas). En el caso del centón, el Fénix es, al mismo tiempo, la Virgen María que encarnó a Cristo y de esta manera posibilitó su sacrificio y resurrección, y el templo de la Inmaculada, que, a su vez, da cabida al culto a Jesús Nazareno. La parafernalia mitológica del ave Fénix resultó una eficaz alegoría del misterio de la Redención. 
el caso del verso de la Fénix, también funerario (al sepulcro de El Greco). Como el pincel del Greco dio "espíritu al leño y vida al lino" en sus pinturas, la Virgen dio espíritu al leño, la cruz (gracias a que nació de ella, Cristo pudo cumplir la misión de morir en la cruz y salvar a la humanidad), y vida al lino, "carnita" (vida humana) a los pañales del Niño Dios. Muy elocuente forma de cifrar la historia providencial, el misterio de la Redención y el relevante papel de la Virgen en esa historia. Relevancia que no puede más que confirmar su posición privilegiada, su exención del pecado original, o sea, su Inmaculada Concepción.

Una curiosa nota final: los centones de Guevara y de Ramírez de Vargas terminan con el cortesano apóstrofe al virrey, por cuyos buenos oficios se concluyó la construcción del templo:

El tiempo vuela: goza, pues, Bellísima, pues, tu* magnificen[ahora,

los lilios de tu aurora; goza lo que te ofrece [cia, del gran pastor de pueblos que Por este culto, bien nacido pra[enriquece.

Ampáreme tu sombra, pere- ya en nuevos campos, * goza, [grino, y votaré a tu templo mi camino los lilios de tu Aurora; (Guevara, vv. 127-132). goza sus bellas plantas, que maravillas tantas (bien que milagros desprecian[do egipcios) admiraciones son y desenojos, néctar del gusto y gloria de los [ojos (Ramírez de Vargas, vv. 139-148).

Llama la atención el factor de preferencia en este muy cortesano cierre: ningún verso del Panegírico al duque de Lerma, la composición más representativa de la cortesanía de Góngora. Los versos proceden, en su mayoría, de sonetos, y de los petrarquistas; también provienen de canciones y de las Soledades.

El factor de preferencia de López Muñiz responde al mismo patrón, pero la intención es muy diferente. Figuran también los versos "goza, pues, ahora / los lilios de tu Aurora", "admira- 
ciones son y desenojos, / néctar del gusto y gloria de los ojos", para referirse a la admiración que provoca la bella arquitectura del edificio terminado. Sin embargo, el centón no concluye con un apóstrofe al virrey, sino al propio templo,

do halló reparo, * rico albergue luego, descaminado, enfermo, * sordo y ciego; porque a tanta salud se ha restituido tu hermosura, * la Aurora, el Sol dorado coronan de belleza * en nuevo oriente: ella, de flores la rosada frente, él de encendidos rayos coronado.

Este, pues, Sol * con rayos y con flores, ciñendo el tronco * con rayada espina, pacífico se esconde * o se reclina (wv. 80-89).

Quien ande descaminado, esté enfermo, sordo o ciego, encontrará en el templo, ya sea que se esconda (se acoja a sagrado) o se recline (sólo vaya a rezar), el doble amparo de la AuroraVirgen, "de rosada frente" y del Sol-Cristo, "de encendidos rayos coronado". El centón de López Muñiz es el más corto y, quizá por esto, el mejor estructurado y con el tratamiento más original ${ }^{37}$.

\section{LOS CENTONES DEL TRIUNFO PARTÉNICO}

El Triunfo parténico es otro certamen más a la Inmaculada Concepción. Fue convocado por la Real y Pontificia Universidad de México y publicado en 1683; su secretario fue nadie menos que Carlos de Sigüenza y Góngora. Por muchas razones es éste

${ }^{37}$ Como ya dije, los tres centones obtuvieron primer lugar. Guevara recibió como premio una bandeja de plata, con el siguiente epigrama: "Toma el premio y no presumas, / que más te has de aventajar, / pues muchos pueden volar / valiéndose de sus plumas. // Si algún poeta te hurtara / conceptos, en alta esfera / sus versos ennobleciera, / siendo ladrón de Guevara" (f. 18v). Ramírez de Vargas recibió un jarro de plata y este epigrama: "Sólo tu ingenio primero / pudo en centón o retazos / a Góngora hacer pedazos, / dejándolo tan entero. // Si el verso se dividía, / desmayaba su pureza; / mas les distes entereza / igual a la que tenía” (f. 20v). Finalmente, López Muñiz obtuvo otra bandeja de plata y este epigrama: "Don Félix, vuestros centones / nos tienen muy admirados, / que aunque versos remendados, / no son versos remendones. // El premio toman sin queja, / y vuestra Musa fiel / lo reciba, pues con él / le ha venido su bandeja" (f. 22r). 
uno de los certámenes más importantes de la Nueva España: por su secretario (que se lució con las peripecias alegóricas para relacionar la épica de la Eneida con la Inmaculada Concepción); por la altísima participación (más de 500 poetas, según Sigüenza); por la suma de poesía, y de poesía gongorina, que representa; por la importancia social de la patrocinadora (la Universidad); por lo que significó para la acelerada carrera político-eclesiástica de Juan de Narváez, rector a la sazón ${ }^{38}$. Todo esto aunado al trend topic que era la doctrina mariana.

Dice el padre Francisco de Florencia en una de las aprobaciones:

Viven las cosas humanas, dice san Jerónimo, dos vidas: una que les da el ser y otra que les da el crédito; con aquélla viven para sí una vida desaprovechada; con ésta viven una vida provechosa para los otros; de que infiere por legítima consecuencia que no nos hemos de contentar con el ser solamente, si no parecemos lo que somos para otros. Non satis est esse, sed videri: nobis enim necessaria est vita nostra; aliis fama nostra. De qué le hubieran servido a la Real Universidad mexicana tantas piadosas demostraciones con María santísima en el punto de su Inmaculada Concepción, tantas suntuosas finezas, tantos aparatos festivos, como constan de esta ajustada y curiosísima Relación, si por haberlos echado en olvido el silencio (siendo entre las católicas universidades de las que más se han esmerado en su culto) era su piedad la que entre todas se echaba menos (Triunfo parténico 1683, s.f.).

38 Cuenta Sigüenza y Góngora que ningún doctor de la Universidad quería aceptar a Narváez como rector, porque no cumplía con el criterio de la edad (era demasiado joven). Se tuvo que recurrir al virrey conde de Paredes para que se dispensara el requisito: "En el segundo escrutinio [para rector en 1681], el doctor don Juan de Narváez presentó un mandamiento del excelentísimo conde de Paredes, marqués de la Laguna, virrey de esta Nueva España, en que habilitó, en nombre de su Majestad, concediendo venia de edad a los doctores que se hallasen con veintiocho años de edad" (De la Plaza 1927, t. 2, p. 185). Nada más se estrenó como rector, Narváez se propuso rescatar la pompa de las fiestas inmaculistas: "Finalmente, el mayor beneficiado de las fiestas de 1682 en esta carrera de intereses fue el mecenas Juan de Narváez, quien se sirvió de ellas para conseguir ascenso y prestigio: aún no concluía su segundo período de rector, cuando vacó la cátedra de Biblia, la segunda en jerarquía de la Facultad Teológica, presea que siempre había anhelado, pero que exigía una dilatada carrera de oposiciones. En tan propicia ocasión renunció al cargo para concursar, y ganó. Habiendo conquistado los máximos honores en el estudio, y con el Triunfo parténico como auténtica «relación de méritos», ya podía el nuevo catedrático iniciar su carrera externa” (Rubial y GonzÁlez González 2002, p. 151). 
La idea, que se completa en las siguientes líneas, es que no era suficiente que la Real Universidad hubiera celebrado con tanto aparato la Inmaculada Concepción, si la relación de esas celebraciones no se hubiera publicado; esto es, para la Universidad era suficiente el hecho de haber festejado a María, pero era necesario que los demás lo supieran, de ahí la elaboración y publicación del Triunfo. Este escrúpulo del padre Florencia ya es significativo.

Los centones forman parte de una de las secciones del Certamen IV. El asunto es el siguiente:

Reverente se acogió Eneas con toda su armada troyana a Delos, en donde halló quieta estación en lo abrigado de sus riberas Huc feror, haec fessos tuto placidissima portu accipit; egressi veneramur Apollinis urbem [En., III, vv. 78-79]. Y remunerando el dios sus piadosos cultos, le respondió en un oráculo que de su real estirpe vería fecunda propagación el ámbito de la tierra, sin que hubiese en el orbe corona que no ciñese las sienes de su descendencia, ni cetro que no ocupase sus diestras con permanencia durable: Hic domus Aeneae cunctis dominabitur oris, et nati natorum et qui nascentur ab illis [En., III, vv. 97-98]. Sabido es cuánto debió este misterio al austríaco Eneas monarca de dos mundos, el gran Filipo, ya afianzándolo en los corazones españoles con sus decretos, ya impetrando en su favor letras apostólicas para todo el universo católico, cuya ardiente devoción, navegando el golfo de su reinado, soltó las áncoras de su esperanza en el puerto seguro de María Inmaculada. Late esta misma en las augustas venas de nuestro católico rey y señor Carlos II (que Dios guarde), heredada juntamente con la monarquía. Y porque no deben menos estas religiosas demostraciones en culto del misterio al excelentísimo señor conde de Paredes, marqués de la Laguna, virrey y capitán general de esta Nueva España, se volverá el mismo oráculo de gentil en cristiano, celebrando la devoción de su Excelencia, y asegurando en el patrocinio de la Virgen purísima gloriosa sucesión... (Triunfo parténico 1683, ff. 72r-73v).

La ecuación alegórica tiene tres elementos: un pasaje de la Enei$d a$; el papel de Felipe IV y su descendencia en la defensa de la Inmaculada Concepción; los augurios de fecunda sucesión al virrey conde de Paredes, puesto que él también es un defensor de la Inmaculada.

Las noticias provienen del lib. III de la Eneida, wv. 68-98. Este tercer libro comienza con Eneas que, refugiado en la ciudad de 
Antandro, reconstruye su armada con los compañeros fugitivos de Troya, y se dirige a Delos, isla que "depara a los cansados la más plácida acogida en su puerto seguro" (v. 78). Eneas va a orar al templo de Apolo Timbreo (deidad venerada en Delos) y escucha el siguiente oráculo: "Sufridos descendientes de Dárdano, la tierra primera en ver brotar la estirpe de vuestros ascendientes será la que os acoja en su fecundo seno a vuestra vuelta. Id a buscar a vuestra antigua madre. Allí el solar de Eneas ha de señorear el orbe entero, lo mismo que los hijos de sus hijos y los que de sus hijos nacerán" (vv. 93-98).

El "gran Filipo" es Felipe IV, padre de Carlos II. Según Juan Isaac Calvo Portela (2013, pp. 157-158):

la actitud de los Austrias menores [los monarcas que siguieron a Felipe II] respecto al culto de la Inmaculada Concepción fue radicalmente distinta a la de sus predecesores. La Monarquía Hispánica, que desde Felipe II se había convertido en la gran defensora de la catolicidad, tenía por estandarte la Eucaristía, pero, desde estos momentos, junto a ésta va a tener a la Inmaculada Concepción. Para los monarcas, la proclamación como dogma de la doctrina, se va a convertir en la piedra angular de la política exterior en Roma... Para ello, Felipe III, Felipe IV y Carlos II van a convocar una serie de Reales Juntas, en las que se decidió el envío de embajadores extraordinarios a Roma con el fin de lograr la declaración del misterio como dogma de la fe ${ }^{39}$.

La petición de descendencia para los virreyes tiene que ver con el hecho de que la virreina había tenido dos abortos. Sigüenza sólo está deseándoles que pronto tengan el añorado heredero.

Un poco enrevesada, la alegoría propuesta por Sigüenza y Góngora es Carlos II como un nuevo Eneas que, con su imperio sobre el Nuevo Mundo, heredado de Felipe IV, expande el reino y la descendencia de españoles y católicos, gracias al oráculo, o sea, a su muy especial devoción a la Inmaculada Concepción

39 Por su parte, Juan A. Martínez Puche (2004) califica a Felipe IV de "decidido defensor de la Inmaculada" y cita una carta del monarca, dirigida a sor María de Jesús de Ágreda en la que expresa su deseo de lograr que se proclame dogma la Inmaculada Concepción: "Si yo tuviera la dicha de ser medio para conseguir hacer este servicio a Nuestra Señora, viviera y muriera con el mayor consuelo del mundo, y ofrezco de muy buena gana a sus pies mi vida, si con ello pudiese conseguir esta dicha..." (p. 131). 
(la Virgen es Delos; Apolo, Cristo ${ }^{40}$ ). La petición concreta es, entonces, celebrar la devoción a la Inmaculada del virrey conde de Paredes.

Con este asunto debía componerse un soneto en ecos, una canción a imitación de la gongorina En roscas de cristal serpiente breve, que había de formarse "de centones, sacados precisamente del mismo don Luis de Góngora. Y se advierte a los poetas ser indispensable y expresa ley el que no sólo no se han de tomar dos, ni tres versos, pero ni aun uno entero para subrogarlo en la canción" (f. 75r); es decir, no se pueden usar versos enteros: sólo hemistiquios. Como puede verse, la composición exigida es una "gongorinada" exponencial: imitar la canción "En roscas de cristal serpiente breve...": cuatro estancias de diecisiete versos cada una, con un solo heptasílabo, más o menos al centro, con rima ABCBACCdDEFFGGEHH, más una represa de cinco. La canción debe ser, además, un centón de versos de Góngora. El ejercicio es mucho más difícil que el requerido en el certamen anterior, donde se trataba de silvas, metro que ofrece bastantes libertades por ser aestrófico. Como en el caso de Empresa métri$c a$, aquí también se exige que se coloquen en los márgenes las referencias de donde proceden los hemistiquios ${ }^{41}$.

${ }^{40}$ De hecho, el núcleo alegórico del Triunfo parténico es la asociación Delos-María, Cristo-Apolo/ Sol, según argumenta, muy erudita y astutamente, Sigüenza: "Delos (en un tiempo Asteria, beldad mucha en breve mapa que, vistiendo plumas y batiendo alas, cruzó con su remonte la faz de las esferas, y tocando del Egeo las espumas, según Calístenes, quedó isla en metamorfosis gloriosa) fue regazo en que nació Apolo, cuna en que se arrulló Febo y patria noble del sol. Agradecido este Dios, regració a su albergue piedades, llenando a Delos de privilegios. Descolló eminente entre otras islas que la coronaron con hermoso ámbito: In Aegeo (dice Estrabón) magis Delos eminet, circunstant illam Cyclades [Geografía, X]. Y siendo todas a los espíritus del viento vagas y a los embates de las ondas inconstantes, sola Delos, prevenida de los auxilios de Apolo, existió preservada de sacudirse a los golpes de Tetis y estremecerse a la colisión de los aires, siempre firme y nunca titubeante; como las demás islas materiada, pero constante como ninguna" (f. 50r-v). Asteria era una isla errante. Cuando Leto, seducida por Zeus, no encontraba dónde dar a luz, su hermana Asteria la recibió. Allí nacieron Apolo y Diana. Como agradecimiento, Apolo la convirtió en una isla firme con el nombre de Delos, que, a diferencia de las demás Cíclades, no la mueven vientos ni tormentas. La Virgen es Delos porque de ella nació Cristo; Cristo es Apolo y, así como Delos fue premiada quedando fija, María lo fue al quedar exenta del pecado original, mientras el resto de la humanidad está sujeto a los embates del pecado.

41 Usan la edición de Hoces 1654. 
El centón-canción de Francisco de Ayerra y Santamaría obtuvo el primer lugar. En la primera estancia, el poeta traza la alegoría entre Eneas, saliendo del incendio de Troya, cargando a la diosa Vesta a hombros, con el virrey, que, simbólicamente, carga en sus hombros la devoción a la Inmaculada. Ese valeroso Eneas embarcado en su "robusto pino", pone "ley al mar" y "no hay cabo que no doble" 42 . Este último "hemistiquio" es una ingeniosa, y debo decir, hermosa reconfiguración del pasaje gongorino. El verso procede del epilio conocido como "Discurso de las navegaciones" de la Soledad I. Ahí Góngora habla de la pericia de los marineros que, fiándose de la brújula, no hay camino, por ignoto o peligroso, que no emprendan. Así, nada detiene al virrey en su "cruzada" en defensa de la Inmaculada:

El príncipe troyano * el hurto noble, de lo que ilustre luego en el farol de Tetis * hurtó al fuego, parte a llevar* en tan inciertos mares: deidad que en isla * Delos algún día ínclito es rayo, * métrica armonía, término fue * deste prudente Numa que a sus aras llegó, * pureza suma, orbe ya hermoso de sus * patrios lares, esfera celestial * donde devoto peregrino gentil * cumplió su voto

(Triunfo parténico 1683, ff. 76v-77v, vv. 7-17).

Como se trata de hemistiquios y no de versos completos, el factor de preferencia, necesariamente, se amplía. Ayerra "zurce" "retazos" de todas partes: sonetos (muchos), las octavas a san Ildefonso, una que otra canción y uno que otro pasaje de las Soledades-este patrón de selección se repite en todas las estancias de la canción.

Podría pensarse que pegar hemistiquios es más difícil que ligar versos completos, pero me parece que no es así. En realidad, ninguno de los dos poetas, ni Ayerra, ni Ramírez de Vargas (segundo lugar), toman propiamente hemistiquios, es

42 Ayerra y Santamaría hizo un poco de trampa. En realidad no tomó, propiamente, un hemistiquio, sino un verso completo al que le quitó un término: "no hay tormentoso cabo que no doble" (Sol. I, v. 395). 
decir, no parten el endecasílabo en la sexta sílaba (equivalente a la cesura pentemímera del hexámetro latino), sino que recurren a sintagmas, verbales o nominales, que no necesariamente forman un hemistiquio. De esta manera se asegura la lógica gramatical, pues el sintagma nominal puede funcionar como sujeto o complemento (directo, indirecto o circunstancial) del nominal. Por ejemplo, el v. 61 del centón de Ayerra "que ilustran * a los cielos los fanales": tres sílabas más ocho, no auténticos hemistiquios $(5+6$, o viceversa); la primera parte es el sintagma verbal y la segunda sus complementos directo e indirecto. De esta manera, es más fácil formar un verso completo con sentido y pegarlo a otro construido de la misma manera. Un verso entero tiene ya su estructura, no sólo fonética, sino sintáctica y semántica; trabar esa unidad con otra con su propia sintaxis y semántica es mucho más difícil que "pegar" sintagmas sueltos.

El príncipe troyano es Eneas, aquí representación del virrey, y el "hurto noble" debe referirse a la estatua de la diosa Vesta, que, huyendo del incendio y destrucción de Troya, Eneas se llevó junto con su padre Anquises; aquí esa diosa Vesta es alegoría de María, y Anquises, del linaje del virrey. Por su parte, Numa -segundo rey de Roma, autor de varias reformas culturales y religiosas- se relaciona con el marqués de la Laguna por su protección y devoción hacia la doctrina de la Inmaculada Concepción. Este segundo y mejor Eneas llegó, como "peregrino gentil", a sus "patrios lares" (Nueva España) y "cumplió su voto".

En cuanto llegó a Delos, Eneas visitó el oráculo de Apolo, que le prometió un gran imperio y numerosa e ilustre descendencia. Así al virrey, ya en Nueva España, gracias a su devoción inmaculista, Dios le promete eso mismo:

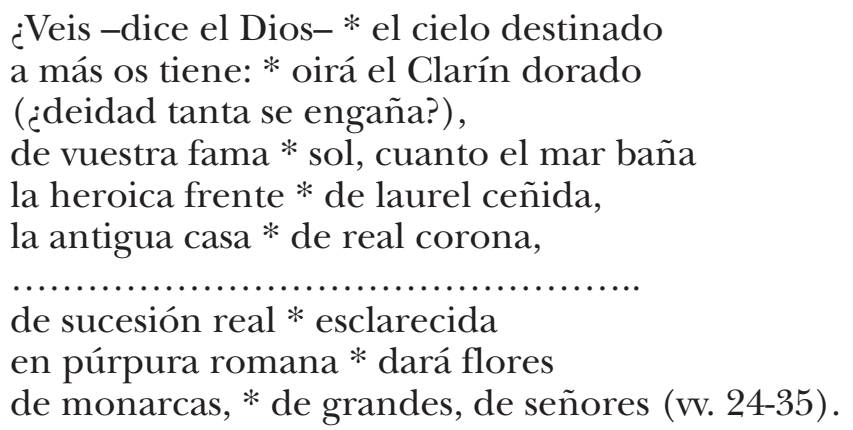


Toda la tercera estancia es un muy cortesano apóstrofe lírico al virrey y a su esposa; y, como en todo discurso epidíctico, con registro del linaje:

¡Generoso esplendor, * oh tú, de España!, firme columna, * estrella de Medina, de los tres lilios reales * copia bella, soberana beldad, * si no divina, de aquella hermosa flor * que te acompaña, dos lucientes estrellas * la que sella, delante quien el sol * aun no es estrella... (vv. 36-42).

La "generosa flor" que acompaña al virrey es, por supuesto, la virreina. Para acabar de entender el encomio, hay que recordar que el virrey conde de Paredes, marqués de la Laguna (Tomás Antonio de la Cerda) fue el cuarto hijo de Antonio de la Cerda, duque de Medinaceli, y que la corona española tenía tres puntas, cada una decorada con un lirio.

Sólo en la cuarta estancia hay una mención explícita de la Inmaculada:

No es voz de deidad ésta consultada, que el que idolatra Delos * más ardiente dora el sol * en oráculo profano; de la Virgen * al templo indeficiente debéis con gran razón * edad dorada, ¡oh claro honor * del freno mexicano! (vv. 53-58).

Lo que dice este pasaje es que la devoción a la Inmaculada no es como la consulta a un oráculo pagano, puesto que este oráculo viene de la Delos/ Virgen María, y del Apolo/ Cristo, lo que asegura prosperidad para el gobierno de los marqueses de la Laguna.

Por lo demás, prácticamente no hay centón, ni de la Empresa métrica, ni del Triunfo parténico, que no incluya la iunctura "freno mexicano"; y es que parece que Góngora la construyó para que fuera centonizada por los poetas novohispanos. El verso se encuentra en el soneto "A la embarcación en que se entendió pasaran a Nueva España los marqueses de Ayamonte”. Se suponía que los marqueses de Ayamonte serían virreyes de Nueva España. Góngora les compuso este soneto de despedida. Aquí habla de la futura virreina como "soberana beldad, valor divino" (verso que Ayerra toma en la tercera estancia para hablar de la virreina con- 
desa de Paredes), y del futuro virrey como "moderador del freno mexicano". ¿Qué otra cosa es el virrey de Nueva España sino el que lleva las riendas del gobierno mexicano ${ }^{43}$ ?

Como ya dije, el centón de Ramírez de Vargas ganó el segundo lugar, a pesar de que es muy superior al de Ayerra y Santamaría $^{44}$. Por un lado, el andamiaje alegórico es mucho más fino y sutil; por otro, los hemistiquios fluyen, no sólo sintáctica y semánticamente con gran naturalidad, sino con ritmo, con

43 El premio de Ayerra fue una fuente de plata y estas redondillas: "Por que a Góngora corone / tu poema, satisfecho / con los centones que ha hecho / tu ingenio, es razón se entone, // por ser el mayor pincel / de Apolo, según arguyo, / darle fuente a un papel tuyo / ha sido gran papel" (Triunfo parténico 1683 , f. $76 \mathrm{v}$ ).

44 Estoy segura de que hubo favoritismo. No sé qué pretendía Sigüenza quedando bien con Ayerra y Santamaría, pero sus alabanzas al personaje rayan en la desmesura (a pesar de la cortesanía propia de los certámenes). En las redondillas citadas en la nota anterior le dice que Góngora estaría satisfecho de haber sido centonizado por él. Podría pensarse que es el halago de cajón por haber obtenido el primer lugar. Pero antes, Sigüenza escribió: "Regocijóse también la ciudad la tarde del día diez y ocho de enero, en que con no menor pompa y lucimiento se publicó el Certamen poético, de que ya dije, y cuya composición para que fuese acertada se encomendó al licenciado don Francisco de Ayerra Santamaría, y, aunque es el animae dimidium meae [Horacio, Odas, lib. I, od. 3, v. 8] que de su querido Virgilio decía Horacio, ninguno que conozca me censurará de apasionado, si digo que es elegante latino, poeta admirable, agudo filósofo, excelentísimo jurisconsulto, profundo teólogo, orador grande y cortesano político, realzándosele todas estas perfecciones con ser una erudita enciclopedia de las floridas letras, y tanto que de él mejor que del otro, a quien alababa Volusiano, se puede decir: Legi deest, quidquid ab hoc contigerit ignorari [cf. SAN AGUSTín 1836, t. 2, p. 597], y no es mucho, cuando por él, en esta línea de que hablo, escribió Claudiano..." (Triunfo parténico 1683, f. 48v). Es tan descarado afirmar que de Ayerra se pueden decir cosas superiores que de san Agustín (el de Hipona es "el otro a quien alababa el Volusiano"), que, en el ejemplar que uso, perteneciente al Fondo Reservado de la Biblioteca Nacional de México, desde "y tanto que de él mejor que de otro..." hasta "Claudiano" está tachado, y alguien escribió a mano en el margen: "No sea algún extraño". Es decir, ¿quién es Ayerra en comparación con san Agustín? Irving A. Leonard (1949, p. 291) comenta: "El padre Sicardo, agustino, cayó en la cuenta de que don Carlos hacía en estas palabras una comparación con el fundador de su orden, el sagrado san Agustín, que desprestigiaba notablemente, en su opinión, al venerable santo, e indignado, denunció la cita en la Inquisición”. Dice el mismo estudioso que el 28 de noviembre de 1683 el Santo Oficio dictaminó que se borrara la proposición denunciada. Aunque "parece que no se logró tachar las líneas denunciadas en todos los ejemplares de la tirada, pues los que poseían los señores Manuel Toussaint y Federico Gómez de Orozco en México en 1940 estaban limpios" (p. 292). 
una musicalidad bastante bien lograda, digna del modelo. Las dos primeras estancias proponen el primer elemento de la alegoría: la salida de Eneas hacia Delos, su llegada y el refugio que ahí encuentra:

Con naval pompa * de inquïeto lino, velero bosque * aun contra el viento armado, la prora diligente $*$ en poca arena no sólo dirigió, * descaminado, el príncipe troyano * peregrino, mas redújola * entre una y otra almena, tocó las playas, mas * fue de su pena término luminoso: que, fuego él expirando, * afectüoso Delos, campos apenas * ha ofrecido, do halló reparo * agradecidamente, cuando de amor * admira, reverente, deidad que en isla $*$ se venera culta, triunfando * del agua que la oculta aun contra el * Orión humedecido; que ser quiso en * el mar sin cobardía al frigio, muro * y resistencia al día

(Triunfo parténico 1683, ff. 78r-79r, vv. 1-17).

Antes de explicar la estancia, son necesarias varias aclaraciones relacionadas con la muy especial gramática gongorina y las muy leves modificaciones que Ramírez de Vargas hace en algunos casos: 1) "mas redújola": como sucede frecuentemente en Góngora, reducir es un cultismo semántico, o sea, está usado en el sentido latino de reducere: "traer de regreso, traer consigo' ${ }^{45} ; 2$ ) "tocó las playas, mas...": en la edición que se supone están usando los concursantes, este verso (f. 11r), segundo del soneto que comienza "No destrozada nave en roca dura", se lee "tocó la playa más arrepentida", y así está en la ya citada edición de las Obras completas. Además de la trampita de hacer plural "la playa", tal vez ese más, adverbio de cantidad en el original, en el centón funcione mejor como conjunción adversativa: después del naufragio, Eneas, peregrino, descaminado ("perdido'), por fin toca tierra; "pero" ("mas") esa

45 “"[El pastor] los bueyes a su albergue reducía, / pisando la dudosa luz del día" (Polifemo, vv. 71-72); "La prora diligente / no sólo dirigió a la opuesta orilla, / mas redujo la música barquilla..." (Soledad II, vv. 49-51). 
llegada a playas extrañas (a Delos, como descubrirá después, donde le darán amparo), se convierte (aunque él, perdido y espantado, aún no lo sepa) en el término feliz de su travesía; 3) "se venera culta": "culta" aquí es participio del verbo latino colo 'venerar'; la expresión en Góngora (Soledad II, vv. 198-199: “...albergues, donde la humildad contenta / mora, y Pomona se venera culta") no es pleonástica: puesto que se trata de una alabanza a la horticultura del lugar, Pomona se venera "cultivada"; aquí sí tiene un valor enfático: la deidad de Delos (la Virgen) se venera "culta", esto es, rindiéndole culto ${ }^{46}$; 4) "y resistencia al día": este segundo hemistiquio se puede aclarar a partir del original gongorino; el cansado peregrino llega a un lugar donde "el fresco de los céfiros rüido, / el denso de los árboles celaje, / en duda ponen cuál mayor hacía / guerra al calor o resistencia al día" (Soledad I, vv. 536-539); es decir, quién refrescaba más al peregrino, el aire de los céfiros o la resistencia que oponía el follaje a la luz del sol. Aquí significaría que no se puede determinar si Delos fue para Eneas más "muro contra el mar" (después del naufragio) o más refugio seguro (por el favorable oráculo) ${ }^{47}$.

Aclarados estos puntos, podemos, ahora sí, intentar una paráfrasis de esta primera estancia: después de un naufragio, el perdido ("descaminado") y peregrino Eneas (el "príncipe troyano") no sólo dirige su nave en poco espacio ("en poca arena"), sino que la regresa consigo hacia playa segura, en donde alcanza a entrever un palacio ("entre una y otra almena"); esa playa fue el final de su doloroso peregrinar. En ese lugar, Delos, que despedía, como ofreciendo afecto al peregrino, el calor de sus altares y hogares, Eneas, agradecido, encontró descanso. Ahí, desde lejos, todavía semioculta por el agua, admiró con reverencia a la deidad que en la isla se veneraba. En medio del mar y de las tribulaciones de Eneas, Delos quiso ser el muro al que pudiera asirse el frigio para protegerse del mar, y cobijo ("resis-

46 Sería uno de esos adjetivos que Borges (1993 [1926]) llama "obligatorios", como decir "monte montuoso" o "luna lunera": "No hay precisión ni novelería en estos adjetivos obligatorios, pero tal vez hay algo mejor. Hay un enfatizar las cosas y recalcarlas, que es indicio de gozamiento" (p. 113).

47 Para este mecanismo de la técnica centonaria es útil la reflexión de STEPHen Hinds (1998) sobre la alusión (pensemos que el centón es una red alusiva llevada a su máxima posibilidad): frecuentemente, para entender la función del verso aludido o referido, es importante enfatizar "the processes of intertextual negotiation" (p. 21). 
tencia al día”) para su cansancio. (Pido al lector que tenga en mente que todo esto se va a relacionar con un Eneas, que es el virrey conde de Paredes, una Delos, que es la Virgen María, y un oráculo de un Apolo/ Cristo. El centón sólo funciona si se actualizan al mismo tiempo los dos niveles de lectura).

En la segunda estancia, Eneas llega a Delos. Pisa la orilla amena, la parte más segura del mar siempre sonante. Ahí le habla dulcemente un oráculo: el Dios omnipotente ofrece a su ardiente deseo la suma felicidad, el más alto trofeo; le asegura que, con el paso del tiempo ("Edades ciento ahora prorrogando"), en la sangre de real linaje de su esposa, que espera ser madre dichosa, el clarín de la Fama hará célebre su ilustre nombre: "aljófares sudando" la madre será fecunda; el mundo, entonces, verá multiplicarse sus imperios, ciento a ciento, hasta el fin del orbe ("el último elemento"):

Edades ciento ahora * prorrogando

fía que en sangre de * Real venera

Madre dichosa, * ya que serlo espera,

Clarín, y de la Fama repetido,

ilustrará * tu nombre esclarecido,

fecunda Madre, * aljófares sudando, verá la gente * el último elemento multiplicarse imperios * ciento a ciento (vv. 27-34).

Las dos últimas estancias, antes de la represa, proponen el segundo elemento de la alegoría; la cuarta con la mención de la ascendencia del virrey: Felipe IV, Carlos II, campeones defensores del "oráculo no profano", o sea, de la Inmaculada Concepción:

No es voz * en oráculo profano, no a deidad fabulosa $*$ consultada esta, pues, gloria * a la inmortal memoria, sino de la razón * edificada, que admira el cielo: * coro soberano suénela * y del olvido haya victoria, monarca * concedido a mayor gloria. De tierra no oprimida, ofrece al gran Filipo, * agradecida, de sucesión real * alta esperanza esta divina * ya con verdad suma Delos, dos mundos, * una y otra espuma; 
porque, $\operatorname{celoso}^{48}$, * a luz de este hemisferio

le mereció * este altísimo Misterio

el celo ardiente * y empuñar la lanza

Carlos, darte el valor, * alta reseña,

mudo ejemplo * devotamente enseña (vv. 35-51).

Como ya dije, Eneas (el virrey) no escuchó la voz de un oráculo profano; la promesa de la gloria de la inmortalidad no es el resultado de la consulta a una deidad de fábula, sino a una deidad edificada en la razón, a una deidad que el cielo admira (la Inmaculada Concepción). Que la cante, pues, el coro soberano y quede el olvido derrotado en este monarca destinado a grandes glorias $^{49}$. Esta tierra divina, Delos (Nueva España), no oprimida, sino agradecida, ofrece la esperanza de descendencia real, en dos mundos, a uno y otro lado del océano.

Finalmente, lo que dice la última estancia es que este nuevo Eneas/ conde de Paredes:

En esta, pues, fiándose * glorïosa

corona inmóvil * del candor primero,

Virgen tan bella, * inexpugnable muro,

oráculo en España * verdadero

en cuanto Febo dora, * siempre hermosa,

48 Celoso: "se aplica también al demasiadamente cuidadoso y vigilante de lo que de algún modo le pertenece, sin permitir la menor cosa en contra" (Dicc. Aut., s.v. zeloso).

49 Según cuenta Sigüenza y Góngora en los primeros apartados del Triunfo parténico, la celebración de la Inmaculada, aproximadamente a partir de 1661, se había ido perdiendo. En efecto, Cristóbal Bernardo de la PlazA (1927, t. 2), justo a partir de esa fecha, no menciona nada respecto a preparativos o celebraciones de la fiesta inmaculista. Ya señalé que todo cambió y tomó el cauce correcto cuando Juan de Narváez fue electo rector, en 1681. Dice Sigüenza: "en el primer claustro que presidió [el nuevo rector] propuso la obligación en que se hallaba la imperial Universidad de México de procurar que de entre las cenizas del olvido en que estaba muerta renaciese con presunciones de Fénix la solemne festividad de la Inmaculada Concepción de María santísima, que anualmente, sin perdonar a los gastos, se celebraba otros tiempos" (Triunfo parténico 1683, f. 17r). DE LA Plaza lo confirma: "Lo primero que el doctor don Juan de Narváez trató en claustro pleno de quince de diciembre de este año fue las fiestas de la Concepción Purísima de Nuestra Señora la Virgen María, ponderando que su intención había sido, aun antes de ser electo rector, que se celebrase tan soberano misterio con la solemnidad y pompa que en otras ocasiones se había hecho..." (p. 186). Y recordemos que Juan de Narváez pudo ser rector gracias a que el virrey conde de Paredes eliminó el requisito de la edad. 
de la tranquilidad pisa * seguro

la arena enjuta * o elemento impuro... (vv. 52-58).

Eneas se acoge a esta isla, corona inmóvil (recordemos que Apolo la había fijado), siempre candorosa, como el nuevo Eneas novohispano se acoge a esta Virgen/ Delos, "siempre candorosa" (sin mancha, exenta del pecado original), verdadero oráculo de España y de todo el orbe ("cuanto Febo dora").

La estancia termina con el apóstrofe al virrey, artífice de la celebración y de la publicación del certamen:
Príncipe glorïoso, clarísimo Marqués, * joh digno esposo de beldad soberana!, * dulce en ella vea lograda * tu Casa esclarecida fecunda madre * de laurel ceñida: siendo tuya la voz, * los triunfos cante más firme Apolo * en cítara sonante de cristiano valor, * de amiga estrella, la salud pise el suelo * mexicano, coronada la paz * de Octaviano (vv. 59-67).

Estos últimos versos pueden parafrasearse: "Príncipe glorioso, ilustrísimo marqués, digno esposo de esa beldad, que tu casa esclarecida vea lograda en ella una fecunda madre, ceñida de laurel; que, siendo de tu linaje ( «siendo tuya la voz») el nuevo y más firme Apolo (el hijo) cante (continúe) los triunfos de tu casa con cristiana valentía; el bienestar («la salud») llegue al suelo mexicano, coronado con la paz de Octaviano" 50 .

Como ha podido apreciarse, todas estas composiciones emanan de una doble fuente: el discurso lírico por excelencia, probado, reconocido y reconocible, esto es, el de Góngora, y una

50 Recordemos que el Triunfo parténico reúne dos celebraciones a la Inmaculada, una de principios de 1682 y otra de 1683. Esta canción pertenece a la primera. Ahora, según el Diario de Robles (1946), el primogénito de los marqueses de la Laguna nació el 5 de julio de 1683, así que, para cuando Ramírez de Vargas compuso este centón, la virreina todavía no estaba embarazada; por eso el tono de esperanzada exaltación de una futura maternidad. -Como premio, Ramírez de Vargas obtuvo una "bandeja de plata cincelada" con este epigrama: "El premio con mil abrazos / a tus centones se va: / iqué tal tu valor será, / si a Góngora haces pedazos! / / En él el rigor descargas, / aunque a tu aplauso convides, / si lo partes, lo divides, / lo ejecutas y lo embargas" (Triunfo parténico 1683, f. 79r). 
cuasi-teología mariana difícilmente sostenible y sostenida, argumentada con más fervor (o intereses políticos) que con razones doctrinales. De esta manera, estos poemas ofrecen, por un lado, una doble perspectiva de comparación; por otro, la posibilidad de ver en el ensamblaje de elementos heterogéneos la cualidad y la función o finalidad del centón. Así, entran en juego no sólo la memoria poética del autor, sino también la del lector, que debe ser capaz de apreciar la discrepancia (o concordancia) entre el contexto original gongorino y el nuevo poema, y descubrir el sentido integral en la resolución de la discrepancia o en el reconocimiento de la concordancia. Un side-effect de la técnica centonaria es la creación de nuevas equivalencias retóricas, estilísticas y temáticas:

In short, this is a type of multilayered composition in which any new authorial voice or artistic identity is transparently made up (materially ${ }^{51}$, relationally) from a pre-existing authorial voice (or voices), and as a function of the reader's capacity to register and re-interpret in the new context the meanings and tonalities associated with the remembered-dismembered source (Tucker 2013, p. 153).

Estos centonistas (o centonarios) novohispanos, representantes barrocos de la revitalización de este género, se preocupan por marcar claramente (incluso con las referencias bibliográficas al margen) la tensión entre los dos planos de lectura, entre los dos contextos, el gongorino y el mariano, de manera que subrayan la cualidad fundamental en la recepción del centón. "Tematizan" no sólo la doctrina mariana, sino la relación entre su texto y el de los poemas gongorinos, para demostrar su pertenencia a la escuela del gran poeta, y, en una de ésas, entrar en una especie de emulación, "autentificados" por la lírica del cordobés y la grandeza espiritual del tema mariano.

El centón gongorino es, en efecto, un producto libresco, pero ello no lo excluye de la estética literaria de su momento. Al contrario, su técnica alusiva y "citacional" (si se me permite el neologismo), es una cualidad inherente de toda la poesía barroca (aunque en el centón con una intensidad excepcional) y, especialmente, de la posgongorina. Un comentarista gongorino, Martín Vázquez Siruela, escribió: “¿Quién escribe oy que

51 "Materialmente" porque, recordemos, las referencias bibliográficas de los versos empleados están materialmente escritas en los márgenes. 
no sea besando las huellas de Góngora, o quién a escrito verso en España, después que esta antorcha se encendió, que no aya sido mirando su luz?"52. Parafraseando a André Thill (apud Bažil 2009, p. 84) ${ }^{53}$, en relación con el vínculo entre la poesía tardolatina y la tradición clásica, la lengua poética del siglo XVII, a medida que avanza el tiempo, se convierte poco a poco en una suerte de centón de la poesía de Góngora. Sólo que en el caso de los centones, el hurto es confesado y es el núcleo de su propuesta estética.

Quizá el centón no es parte de la "gran" poesía, sólo un "satélite", usando la hermosa y elocuente imagen de Giovanni Polara (1990, p. 275), que "risplende solo della luce riflessa del grande modello, gli orbita intorno con riverente rispetto, ma come ogni luna sa a volte illuminarsi di equivoche tonalità o rivelare orridi dirupi dall'ambiguo fascino".

\section{REFERENCIAS}

Agustín, san 1836. Opera omnia, Gaume Fratres Bibliopolas, Paris.

Alegre, Francisco Javier 2016. Arte poética de Mr. Boileau traducida a rima castellana por don Francisco Javier Alegre. Ed. Martha Lilia Tenorio, El Colegio de México-Fundación para las Letras Mexicanas, México.

Ausonio, Décimo Magno 1990. Obras. Trad. y notas de Antonio Alvar Ezquerra, Gredos, Madrid, 2 ts.

Ausonio, Décimo Magno 1999. Opera omnia. Ed. R.P.H. Green, Oxford University Press, Oxford.

BažIL, Martin 2009. Centones Christiani, Institut d'Études Augustiniennes, Paris.

Borges, Jorge Luis 1993 [1926]. El tamaño de mi esperanza, Seix Barral, Barcelona.

Calvo Portela, Juan Isaac 2013. "La Monarquía Hispánica defensora de la Inmaculada Concepción, a través de algunas estampas españolas del siglo xviI", Anales de Historia del Arte, 23, pp. 155-168; doi: 10.5209/rev_ ANHA.2013.v23.41908.

Carreira, Antonio 2010. "Góngora y el canon poético", en El canon poético en el siglo XVII. Dir. Begoña López Bueno, Grupo PASO-Universidad de Sevilla, Sevilla, pp. 394-423.

Certamen poético 1654. Viuda de Bernardo Calderón, México. p. 420 .

52 Discurso sobre el estilo de don Luis de Góngora, apud CARreira 2010,

${ }^{53}$ Lo que dice Thill es que la poesía tardolatina fue convirtiéndose gradualmente en casi un centón de versos clásicos, por la abundancia y frecuencia de las alusiones a los grandes poetas latinos. 
Conte, Gian Biagio 1986. The rhetoric of imitation: Genre and poetic memory in Virgil and other Latin poets. Ed. Charles Segal, University Press, Ithaca, NY.

Conte, Gian Biagio 2017. Stealing the club from Hercules. On imitation in Latin poetry, De Gruyter, Berlin.

De la Plaza, Cristóbal Bernardo 1927. Crónica de la Real y Pontificia Universidad de México. Ed. facs. de Nicolás Rangel, Talleres Gráficos del Museo Nacional de Arqueología, Historia y Etnografía, México, 2 ts.

Delepierre, Octave 1868. Revue analytique des ouvrages écrits en centons, depuis les temps anciens, jusqu'au XIxième siècle, Trübner and Co., London.

Dicc. Aut. $=$ Real Academia Española 1984. Diccionario de autoridades, Gredos, Madrid.

Diego, Gerardo 1927. Antología poética en honor de Góngora, Revista de Occidente, Madrid.

Diego, Gerardo 2003. La estela de Góngora. Est. prel. de Julio Neira, Universidad de Cantabria, Santander.

Empresa métrica 1665. Viuda de Bernardo Calderón, México.

ERMnini, Filipo 1909. Il centone di Proba e la poesia centonria latina, Ermanno Loescher, Roma.

Gallardo, Bartolomé José 1889. Ensayo de una biblioteca española de libros raros y curiosos. Imprenta y Fundición de Manuel Tello, Madrid, 4 ts.

Góngora, Luis de 2000. Obras completas. Ed. Antonio Carreira, Fundación José Antonio de Castro, Madrid.

Góngora, Luis de 1985. Sonetos completos. Ed. Biruté Ciplijauskaité, Castalia, Madrid.

Guijo, Gregorio de 1953. Diario 1648-1664. Ed. y prol. Manuel Romero de Terreros, Porrúa, México, 2 ts.

Herrero García, Miguel 1939. Estimaciones literarias del siglo XVII, Voluntad, Madrid.

Hinds, Stephen 1998. Allusion and intertext. Dynamics of appropriation in Roman poetry, Cambridge University Press, New York.

Hinds, Stephen 2014. "The self-conscious cento", en Décadence. "Decline and fall" or "Other antiquity"? Eds. Marco Formisano \& Therese Fuhrer, Universitätsverlag Winter, Heidelberg, pp. 171-197.

Hoces, Gonzalo de 1634. Algunos poemas de don Luis de Góngora, Imprenta del Reino, Madrid.

Infantes, Víctor 1990. "Poesía sobre poesía: España y Portugal entre nuevos centones gongorinos", Claro-Escuro. Revista de Estudos Barrocos, 4/5, pp. 115-124.

Lamacchia, Rosa 1958. "Dall'arte allusiva al centone", Atene e Roma, 3, pp. 193-216.

Lamacchia, Rosa 1996. “Centoni”, Enciclopedia Virgiliana, Istituto dell'Enciclopedia Italiana, Roma.

Leonard, Irving A. 1929. "Some Góngora centones in Mexico", Hispania, 12 , pp. 563-572.

LeOnard, Irving A. 1949. "Sobre la censura del Triunfo parténico (1683) de Sigüenza y Góngora”, Nueva Revista de Filología Hispánica, 3, pp. 291-293; doi: $10.24201 /$ nrfh.v3i3.3193.

Lewis \& Short 2002. A Latin Dictionary, Clarendon Press, Oxford. 
Martínez Medina, Francisco Javier 2019. "Componentes teológicos y contextos devocionales de la Inmaculada”, en La Inmaculada Concepción y la Monarquía hispánica. Eds. José Javier Ruiz Ibáñez y Gaetano Sabatini, Fondo de Cultura Económica, Madrid, pp. 35-59.

Martínez Puche, O.P., José A. 2004. El libro de la Inmaculada. Doctrina, historia, poesía y arte sobre la Inmaculada Concepción de María, Edibesa, Madrid.

McGill, Scотт 2005. Virgil recomposed. The mythological and secular centos in Antiquity, Oxford University Press, New York.

Méndez Plancarte, Alfonso 1945. Poetas novohispanos, Universidad Nacional Autónoma de México, México, 2 ts.

Montes González, Francisco 2016. Mecenazgo virreinal y patrocinio artístico, Universidad Nacional Autónoma de México, México.

OKÁČOvÁ, MARIE 2009. "Centones: Recycled art or the embodiment of absolute intertextuality?”, Kakanien Revisited, 3, pp. 1-7.

PAlmer, AdA 2014. Reading Lucretius in the Renaissance, Harvard University Press, Cambridge, MA.

Parra García, Luis 1999. "Pervivencia del centón en el Renacimiento: Cento ex Virgilio Gallus de Lelio Capilupi”, Cuadernos de Filología Clásica. Estudios Latinos, 16, pp. 363-412.

Pasquali, Giorgio 1968. Pagine stravaganti, Sansoni, Firenze.

Plinio el Viejo 2003. Historia natural. Trad. y notas de Encarnación del Barrio Sanz et al., Gredos, Madrid.

Polara, Giovanni 1990. "I centoni”, en Lo spazio letterario di Roma antica. T. 3: La ricezione del testo. Dirs. Guglielmo Cavallo, Paolo Fedeli e Andrea Giardina, Salerno Editrice, Roma, pp. 245-275.

Ponce Cárdenas, Jesús 2008. "El oro del otoño: glosas a la poesía de Agustín de Salazar y Torres”, Criticón, 103/104, pp. 131-152; doi: 10.4000/ criticon. 11786.

Prieto Domínguez, Óscar 2008. “¿Qué era un centón para los griegos? Preceptiva y realidad de una forma literaria no tan periférica”, Myrtia, 23, pp. 135-155.

Prieto Domínguez, Óscar 2010. De alieno nostrum: el centón profano en el mundo griego, Universidad de Salamanca, Salamanca.

Robles, Antonio de 1946. Diario de sucesos notables (1665-1703). Ed. y pról. de Antonio Castro Leal, Porrúa, México.

Ros, Carlos 1994. La Inmaculada y Sevilla, Editorial Castillejo, Sevilla, 1994.

Rubial, Antonio y EnriQue GonzÁlez González 2002. "Los rituales universitarios. Su papel político y corporativo", en Maravillas y curiosidades. Mundos inéditos de la Universidad, Antiguo Colegio de San Ildefonso, Ciudad de México, pp. 135-151.

Ruiz Ibáñez, José y Gaetano Sabatini (eds.) 2019. La Inmaculada Concepción y la Monarquía hispánica, Fondo de Cultura Económica, Madrid.

Salanitro, Giovanni 1997. "Osidio Geta e la poesia centonaria”, Aufstieg und Niedergang der römischen Welt, 34, pp. 2314-2360.

Salazar y Torres, Agustín de 1694. Cítara de Apolo. Primera parte, Antonio González de Reyes, Madrid.

SAnta Teresa, R.P. SEverino De 1954. La Inmaculada en la conquista y coloniaje de América, Ediciones El Carmen, Vitoria.

Sineri, Valentina 2011. Il centone de Proba, Bonanno Editore, Roma. 
Tenorio, Martha Lilia 2010. Poesía novohispana. Antologia, El Colegio de México-Fundación para las Letras Mexicanas, México, 2 ts.

Tenorio, Martha Lilia 2019. "Centones gongorinos en Nueva España”, (An)ecdótica, 3, 2, pp. 11-46; doi: 10.19130/iifl.anec.2019.2.1146.

Triunfo parténico 1683. Juan de Ribera, México.

Tucker, G. Hugo 2013. "Strategies of argument, politics and poetics in the «Centones ex Virgilio» (1555-1556) of Lelio Capilupi of Mantua", en The art of arguing in the world or Renaissance Humanism. Eds. Marc Laureys \& Roswitha Simons, Leuven University Press, Leuven, pp. 151-186.

VIDAL, José Luis 1973. "Observaciones sobre centones virgilianos de tema cristiano. La creación de una poesía cristiana culta”, Boletín del Instituto de Estudios Helénicos, 7, pp. 53-64.

Virgilio 2003. Obras completas. Ed. bilingüe. Trad. Aurelio Espinosa Pólit, Cátedra, Madrid. 